\title{
Choice of TAX BASE ReVisited: CASH Flow VS. PREPAYMENT APPROACHES TO CONSUMPTION TAXATION
}

\author{
SYED M. AHSAN \\ PANAGIOTIS TSIGARIS \\ CESIFO WORKING PAPER No. 983 \\ CATEgOry 1: Public FinANCE \\ JULY 2003 \\ An electronic version of the paper may be downloaded \\ - from the SSRN website: \\ www.SSRN.com \\ - from the CESifo website: \\ www.CESifo.de
}




\title{
ChOICE OF TAX BASE REVISITED: CASH FlOW VS. PREPAYMENT APPROACHES TO CONSUMPTION TAXATION
}

\begin{abstract}
This paper re-examines the issues involved in the design of a direct tax on consumption, an idea that has received a fair degree of acceptance in the transition countries over the past decade (e.g., tax reforms in Croatia and Moldova). First we argue that on the subject of equivalence among a set of taxes, the only meaningful comparison is along the ex-ante concept of equivalence, and not ex-post. The latter as we shall see requires highly implausible, and often arbitrary, choice scenarios. We carry out the analysis in a variety of models starting with the two-period consumption-saving choice under full certainty. However, a good part of the discussion is carried out where the portfolio choice behaviour is embedded in an intertemporal savings model that has been widely discussed in the literature. We then take up more complete (and necessarily more complex) choice situations for examination. Indeed the first of two variations of the above is a model where individuals make work-leisure (for a given skill level) as well as the safe-risky asset choice. The last is of risky human capital choice, where the physical investment is restricted to a single non-risky asset. For the purposes of the paper, the models are very general, and the precise choice context is open to wider interpretations than how they are actually phrased. In spite of our preoccupation with the efficiency aspects, we are interested in other important issues of equity, and those of an administrative nature. But our remarks on the latter fronts are limited to the insight that we directly gain from the analytics.
\end{abstract}

Keywords: tax reform in transition countries, cash-flow tax, prepayment tax, ex-ante and expost equity, risk sharing, and tax reform.

JEL Code: H30, H43, H63.

\author{
Syed M. Ahsan \\ Department of Economics \\ Concordia University \\ 1455 Boul de maisonneuve Oest \\ Montreal, $Q C$ \\ Canada H3G $1 M 8$ \\ ahsansm@vax2.concordia.a
}

\author{
Panagiotis Tsigaris \\ Dept of Economics and Finance \\ University College of Cariboo \\ 900 McGill Rd., FAA34 \\ Kamloops, B.C. \\ Canada, V2C $5 \mathrm{~N} 3$
}


"Expenditure system of direct taxation ....an idea which periodically circles the world...without ever permanently finding a home." (The Economist, June 28, 1978, p70)

\section{Introduction}

The Economist remark, made while reviewing the Meade Commission report of 1978, is true of major OECD economies (such as the G7). However, if for the advocates of a direct tax on consumption, it is gratifying to note that several transition countries (notably Croatia and Moldova) have been experimenting with the idea over the past decade (Rose, 1998, 1999).

The principal aim of this paper is to re-examine the issues involved in the design of the consumption tax. Thus we shall not review the extensive literature on the income vs. consumption debate except as those elements that may be directly related to the consumption tax design, namely the cash-flow tax, and its equivalent forms. Secondly, the orientation of the paper is analytical; it reviews the exisitng body of theory on the subject, and attempts to extend the analysis in several directions. Certainty as well as risk environments are considered, though more effort is given to the latter endeavour. At the same time, in spite of our preoccupation with the efficiency aspects, we are interested in other important issues, such as equity, and those of an administrative nature. But our remarks on the latter fronts are limited to the insight that we directly draw from the analytics.

The underlying choice framework that we adopt is the standard life-cycle consumption allocation model, both in the certain and in the risk context. We do stress that most issues of a policy focus arise out of alternative possible treatments that one may accord to different categories of assets, and for that reason, the simple two-good model of consumption now and later is inadequate. Additional aspects such as work-leisure choice, asset behaviour as well as human capital decisions are important additions, and we take these up in turn.

Recall that alternative methods of implementing a consumption tax can be generally classified into two categories. The first, the cash flow method, allows a tax deduction for the entire amount saved, while the proceeds (principal and return) become taxable only upon withdrawal. This is widely described as a cash flow tax (CFT). The second is a pre-payment method, whereby individuals pre-pay tax on the total earnings (inclusive of inheritances, if any) in advance, such that savings occur out of net-of-tax resources, and there are no further taxation of the returns from investment. This tax is known as the prepayment tax or PPT. In earlier writings we have proposed an amendment of the latter, which may be called a modified prepayment tax (MPT), where in addition to the prepayment of tax, individuals would face a 
further tax on the eventual value of the extra-ordinary gains. The latter may consist of capital gains, above normal returns, or even a tax on the risk premium on the investment. Note that all extraordinary gains on investment are fully taxed under the CFT base on eventual consumption. In certain simple settings the PPT (indeed a simple wage tax) appears to be equivalent to the CFT in terms of its lifetime claim on a person's available resources. Nevertheless, we have argued that one need to rely on the MPT in order to achieve this equivalence with CFT as a matter of general rule. ${ }^{1}$ Not all writers on the subject agree with our proposal. We offer an extensive enquiry to examine this debate further, and hope to find common grounds with other researchers in the field.

The choice between PPT and MPT, as we shall see, depend crucially on how one appraises the state's ability to shift private risks. Once this is determined one can then obtain guidance as to the value of the social discount rate the public authorities may use. Starting with a simple alternative such as the state being superior to private markets in dealing with risk, we move to one where it is just as able as the private market. And finally, we take up the case where the current revenue risks are dissipated among all future generations to come. Each of these behavioural postulates yields a corresponding risk discount rate. In the process we arrive at a number of rich results. As a by-product of this analysis we hope to provide a reconciliation among the different results recorded by different authors, which may at first sight appear to contradict each other.

While it is often customary to think that since the state is able to borrow much cheaper than the private sector, its discount rate ought to be the lowest. The strongest justification we find for this view arises when we analyse the intergenerational risk sharing behaviour. We find that if members of a given generation may transact with future (including yet unborn) generations via the budget process (namely through public debt management), and if the number of risk sharing generations were many, the social discount rate converges to the risk-free rate. Evidently, the systematic risk facing a given generation becomes idiosyncratic when shared with many future generations.

Overall, the results we get do not all come from the risk models. Even from the pure certainty framework, we find that the standard PPT-CFT equivalence does not go through unless one adopts the "ability to pay" view of economic magnitudes (rather than the "standard of living", as favoured by the Treasury, 1977) especially when gifts and inheritances are involved. In risk models we see that ex-ante tax equivalence (defined to mean equivalence between tax regimes that hold for all plausible behavioural rules) does not hold between CFT and PPT, instead between CFT and MPT. The alternate notion of ex-post equivalence (necessarily holding true for specific behavioural instances) may hold between CFT and PPT, but these we characterise as being fortuitous. The only event where a full-fledged earnings and endowment tax (EET) turns out to be ex-ante equivalent to CFT occurs in a model of risky human capital. But here the former cannot be dubbed a pre-payment tax in any sense of the term since the risky earnings occur after the investment (often, long after, as many doctoral/habilitation scholars find out, especially in Germany!) has already been made. Another result of interest arises in the context of inter-generational risk shifting. We find that a cash flow tax (or equivalently, an

\footnotetext{
${ }^{1}$ See Ahsan (1989, 1990 a, b), and Ahsan \& Tsigaris (1998).
} 
MPT) leads to a Pareto improvement allocation of welfare vis-à-vis the earnings/endowment tax of the PPT mode.

In the equity area, we argue that our analytical perspective suggests that the debate in the literature on ex-ante vs. ex-post equity is a bit misplaced. Both notions of equity are indispensable for credible conduct of public policy, as these are complementary. Both the process as well as the outcome needs to be judged fair in order to achieve overall fairness. Achieving equitable outcome, the focus of most writings, would be hard, as John Rawls have taught us, without an equitable process that allows a level playing field to all.

Finally we offer the insights from our analytical tour to suggest reforms for the consumption tax design in order to improve its political as well as wider social appeal. We find that adding extraordinary gains made on investment under the purview of consumption tax, allowing a full accounting of gifts and bequests, and limiting the number of assets that may be allowed to be treated on a strict prepayment basis, we may succeed in selling the consumption tax idea widely. Each of these arguments is fully developed in what follows.

The rest to the paper proceeds as follows. Section 2 deals with models of certainty, where we begin our discussion of the conceptual basis of measurement and the like. The treatment of gifts and bequests is also analysed here. Then we start the main part of the paper, namely the development of models of risk (i.e., in section 3), where we begin with the standard consumption allocation model with asset choice. We then add the work leisure choice in the same set up. Finally, we replace the financial asset by the risky human capital as the risky asset (and allow a physical asset with a known rate of return). In section 4, we highlight some key results of an efficiency nature. Section 5 deals with the equity implications of our analytical results, and similarly, section 6 is reserved for a few brief remarks on reform and administrative issues. Some concluding remarks are put together in section 7. A short appendix laying out the intergenerational risk shifting mechanism is added next 


\section{The Certainty Paradigm}

\subsection{The Conceptual Aspects of the Direct Consumption Tax Base}

What ought to be the tax base for direct taxation of individuals? It is fair to say that from the 1920s (roughly coinciding with the birth of modern direct tax legislation), the majority of public finance scholars rallied behind income as "the money value of the net accretion to one's economic power" (Haig, 1921, p7, cited by Wildasin, 1990). While Haig is known to be the first English-speaking economist to propose the accretion income idea as a basis of direct taxation, the origin of the concept may be attributed to an 1896 piece written by the German scholar Georg Schanz. ${ }^{2}$ Interestingly, Wildasin (1990) has recently pointed out that while Haig had settled on the accretion income as a practicable measure of "income", he had originally defined income from first principles. In keeping with modern neo-classical economics, Haig conceived of income as the flow of utilities derived from the flow consumption services over a given unit of time; "it is the flow of utility that constitutes true income" (Wildasin, p.651). While it is immediate that "flow of utility" would be hard to pin down as the tax base of choice, he went on to suggest that "..the usances and satisfactions and the goods and services which are of significance to the economist in his analysis are those which are susceptible of evaluation in terms of money" (Haig, 1921, pp 3-4; again cited by Wildasin). In other words, for practical purposes a monetary measure of income "would ideally be the value of current consumption services" (Wildasin, p651).

Hence Wildasin likens Haig as the pioneer advocate of consumption taxation. However that would be less than precise; J. S. Mill is known to have argued in favour of a tax on consumption as being fairer than one of income. In the same article cited above, Haig went on to argue that, never mind "the flow of utilities", even the measurement of consumption expenditure would be too tedious, and hence infeasible! In this he was not alone. Goode notes that while "Marshall, Pigou, Einaudi and other distinguished economists" had endorsed Mill's position on this, they all believed it as not practicable (Goode, 1964, p25). Interestingly, as Rose (1990a) points out, Joseph Schumpeter writing in 1929-30 not only argued in favour of a direct tax on consumption, he even believed it were practicable. "The technical difficulties", Schumpeter stated, “... are big, but not nearly as big as it is stated...The self-employed and the wage earners would have to be demanded to provide proof of investment. Proof which could ninety times out of a hundred be furnished without great effort or loss of time through savings accounts and deposit registrations" (1929-30, [1985], pp. 125-26).

However, at least in the US context, the belief in the infeasibility of the consumption tax, led Haig to develop a "monetary measure" of income, the accretion income. Since that time, economists generally identify the concepts of income and consumption from the well-known identity

$$
Y=C+\Delta W
$$

\footnotetext{
${ }^{2}$ See Richard Goode (1974) for a historical note. Indeed he finds that Davidson of Uppsala, writing even before Schanz, also had a part to play in the development of the concepts.
} 
Adopting the conventional notation, this merely states that (accretion) income is the sum of all consumption and the change in net wealth position of the individual. ${ }^{3}$ The income term would typically consist of earnings as well as the return on physical capital. The wealth stock, W, is to be interpreted as accumulated savings (net of debt). ${ }^{4}$ Indeed the comprehensive income is often labelled Haig-Schanz-Simons (or, at least in the States, simply Haig-Simons) income. Indeed the above identity has been taken to provide the conceptual foundation of the idea of "comprehensive income" that has been argued over the years as the correct tax base for direct taxation of individuals.

It is somewhat ironic that later writers have turned this alleged infeasibility of a direct consumption tax on its head. While Schumpeter had been the real forerunner, David Bradford has taken up this challenge and has argued that "it is the consumption base that has its most obvious administrative advantage" (1980, p.85). We shall see in greater detail below how such a claim may be justified and sustained. For the present, let us simply note that presumably Haig and his generation of economists viewed upon consumption expenditure from the perspective of household outlays. Realising that monetary receipts, absent gifts, bequests and inheritances, may either be consumed or saved, "the annual consumption of a household could be measured without directly monitoring the purchase of goods and services" (Bradford, 1984, p 102). ${ }^{5}$ To see this more formally, let us return to the Haig-Schanz-Simons identity, and following Bradford, we interpret quantities as receipts. Note that wealth holding between two adjacent dates $\left(W_{j}, W_{j+1}\right)$ would be related as follows:

$$
W_{j+1}=E_{j}+(1+r) W_{j}-C_{j},
$$

where $E_{j}$ denotes the non-wealth receipts (such as earnings, transfers etc) and $r$ is the known rate of return on investment. From (2.2), we may write two equivalent statements:

$$
\begin{aligned}
& \left\{C_{j}+\Delta W_{j}\right\}=\left\{E_{j}+r W_{j}\right\} \\
& C_{j}=\left\{E_{j}+r W_{j}-\Delta W_{j}\right\}
\end{aligned}
$$

The first merely says that comprehensive income, $Y$, (the left-hand side) equals the totality of all monetary receipts. The second allows a deduction of the net saving during the period from comprehensive income in order to arrive at the consumption tax base. In other words,

$$
C_{j}=Y_{j}-\Delta W_{j}
$$

Given that the components of both comprehensive income and consumption are identical, how can any one of these concepts be easier to implement than the other? The key

\footnotetext{
${ }^{3}$ The focus of the paper being primarily analytical, we will not necessarily address all relevant issues of policy substance, only to those that are predicated by the analytical results at issue. In this spirit we will refer to the tax unit interchangeably as the "individual" or the "household" since we do not dwell on the choice of the tax unit.

${ }^{4}$ At this stage we shall not dwell on the details of the composition of net worth, or related measurement issues. Indeed we shall turn to selective aspects of these issues later in a section that deals with tax administration and compliance.

${ }^{5}$ The treatment of gifts, inheritances and bequests, as Bradford has noted, is unrelated to the choice of income or consumption as the correct base, and hence may be ignored for the time being. However, as we shall see below, insofar as the design of the consumption tax is concerned, the precise manner of accounting for gifts, bequests and inheritances have both equity and efficiency implications.
} 
difference relates to the measurement of income $\left(Y_{j}\right)$ under a direct consumption tax visà-vis the comprehensive income tax. Specifically, for consumption taxation, there is little need to value the accrued return on assets. Measuring the returns on accrued wealth (e.g., capital gains, pension wealth, life insurance policies, corporate retained earnings) is a complex task, which must be dealt with in computing income (via the right hand side of 2.3a). By contrast true consumption in a given period is based on all cash transactions, and thus completely bypasses the accrual arithmetic. "If no cash transaction takes place", as Bradford puts it, "there is no need to be concerned about those forms of wealth in calculating the base of a consumption tax. It is that simple" (1980, p.85).

\subsection{Alternative Means of Consumption Tax Design}

The consumption base turns out to be rather versatile as to the mode of design. Bradford (1986) enumerates no less than four alternative means, which essentially differ from one another in the manner various asset and non-asset transactions are accounted for in order to measure consumption occurring within a period of time. First is the simple flat tax (proposed by Robert Hall and Alvin Rabushka), which combines a business tax on cash flows (less employee compensation) and another tax at the same rate on compensation earned by individuals (less a personal exemption). Bradford calls this a "two-tiered cash flow tax", which differs from the cash-flow VAT only in that individuals are entitled to a personal exemption on the compensation received from businesses. The next two, labelled a full-fledged cash flow tax, and the Blueprints cash-flow Tax will be reviewed at length in what follows. The fourth one, whereby gradual modifications of the income tax are made in order to make the former effectively resemble a tax on consumption, which may be politically expedient, but has little analytical force behind it, and hence will not be cited further.

2.2.1 A Cash-flow Tax (CFT): Let us turn first to the case of standard cash-flow account of transactions, where all savings must occur within what the US Treasury's Blueprints (1977) called qualified accounts (QAs). ${ }^{6}$ Under this approach, individuals would be entitled to deduct all deposits into the qualified accounts in order to configure current consumption. Likewise they will be obliged to include all withdrawals, regardless of the origin of the withdrawal (principal, interest, dividend, or capital gains) from such accounts. The difference between these two flows being precisely $\Delta W_{j}$. It should be noted that since the registration authority will be a fiduciary organisation, the record-keeping burden of taxpayers would be greatly minimised, as Joseph Schumpeter had foreseen long ago. It is also obvious that several countries have such tax-advantaged saving programs, even though various restrictions and regulations governing such accounts do not necessarily render the underlying tax system one of consumption taxation. Notable examples include the Canadian registered retirement savings plans (RRSPs), Keogh, $401 \mathrm{~K}$, and individual retirement accounts (IRAs) in the States. A strict adherence to the cash flow treatment for all assets has been referred to as full-fledged cash-flow accounting (Bradford, 1986). We will simply call it the cash-flow tax (CFT).

\footnotetext{
${ }^{6}$ In this paper we shall refer to both the original Blueprints for Basic Tax Reform document published by the US Treasury in 1977 as well as the revised second edition published in 1984 by Bradford and the Treasury Policy Staff. For convenience we shall cite the former as Treasury (1977) while the revised document as Bradford et al (1984).
} 
2.2.2 The Prepayment Tax (PPT): The second version of the consumption tax that we will consider here is what has been termed the prepayment tax (Treasury, 1977). In this scheme the asset accumulation is done outside of qualified accounts, i.e., "the investment is not subtracted from the base, and none of the subsequent return flow is included. ...[T] he actual tax liability occurs at the time of the investment (which is, in effect, treated as part of consumption)" (Bradford, 1980, p86). From here on a direct consumption tax based on full-fledged tax prepayment treatment will be referred to as the prepayment tax $(P P T)$. What might be the rationale for devising such an alternative treatment of assets?

The primary logic would appear to be the simplicity of tax administration and compliance. Bradford has argued the above alternative would allow an easy implementation of a direct consumption tax since in his view, individuals do not have to keep track of asset dispositions on a timely basis any longer. The PPT approach comes in especially handy for dealing with the household purchase of durables, including owneroccupied housing. If one were to accord the cash-flow treatment to these assets, the future returns would have to be included. How would one enumerate such flows, especially the value of non-pecuniary services? Bradford et al have further argued that "the price paid for a consumer durable should reflect the present value of future services the buyer expects to receive" $\left(1984\right.$, p109). ${ }^{7}$ Hence such a durable purchase is to be construed as consumption as and when acquired even if the services were to accrue well into the future. This then is tantamount to requiring that the tax due be paid up in advance.

A further, and analytically more significant, justification behind proposing the prepayment alternative to the cash-flow treatment of asset transactions appears to be the claim that "the expected present value of the worker's lifetime tax base would be the same for either method of accounting, if he consumes the proceeds of his account during his lifetime" (Bradford et al, 1984, 103). The Blueprints' authors go on to suggest that even the government would be indifferent. "The consequences to the government of the two ways of taxing the purchase of assets would also be the same in present value terms" (1984, p.111).

The "equivalence" between the two treatments alluded to above may be readily seen using a simple two-period life cycle model of saving behaviour. The period-by-period constraints, absent taxation, are given by

$$
\begin{aligned}
& C_{1}=Y-S, \\
& C_{2}=S(1+r),
\end{aligned}
$$

where consumption in each period is denoted by $C_{j,}(j=1,2)$, and $Y$ is first period income earned by the household by supplying a fixed amount of labour, while total saving is denoted by $\mathrm{S}$. The present value of this budget set may be written as

$$
\left\{C_{1}+C_{2}(1+r)^{-1}\right\}=Y .
$$

\footnotetext{
${ }^{7}$ But this may not be the whole truth; for appreciable assets such as owner-occupied housing, evidence would seem to point out that at least over a long horizon homeowners typically receive sizable capital gains over and above the current non-pecuniary rental services they enjoy during the term of tenure. Much of the gain cannot be construed to have already been reflected in the original purchase price. We return to these difficulties in sections 4 and 5 below.
} 
Under the CFT, consumption in each period would be taxed, say at the rate $t_{c}$, and consequently the post-tax budget set reduces to ${ }^{8}$

$$
\left(1+t_{c}\right)\left\{C_{1}+C_{2}(1+r)^{-1}\right\}=Y .
$$

Now turning to the pre-payment approach, there would be no deduction for saving in period-1. And hence the tax is applicable to the full value of $Y$, with no further taxation in period-2 when the asset is redeemed to finance retirement consumption. One thus obtains the following post-tax budget set:

$$
\left\{C_{1}+C_{2}(1+r)^{-1}\right\}=\left(1-t_{E}\right) Y,
$$

where we have denoted the PPT by $t_{E}$. From the pre-tax budget set (2.5), it follows that lifetime consumption equals the lifetime earnings (the latter accruing in period-1). The two alternatives therefore effectively tax the same base, namely lifetime consumption. From (2.6a) and (2.6b), it is immediate that if tax rates are chosen symmetrically, i.e., such that $t_{c}=\left\{t_{E} /\left(1-t_{E}\right)\right\}$, or, $t_{E}=\left\{t_{c} /\left(1+t_{c}\right)\right\}$, the two budget sets would be identical, and utility maximising agents would make the same choice. ${ }^{9}$

Thus even though the government's revenue realisation path is altered by switching from the CFT to the PPT, in present value terms, there is no difference. From (2.6a) and (2.6b), the present value of revenues in the two cases are respectively given by:

$$
R_{c}=\left\{t_{c} /\left(1+t_{c}\right)\right\} Y \text {, and, }
$$

$$
R_{E}=t_{E} Y \text {. }
$$

Thus given symmetric tax rates, present value tax revenues are also identical between CFT and PPT. Reasoning such as presented here prompted Bradford et al. to suggest that "allowing a deduction for purchases of assets and taxing withdrawals--- the qualified accounts treatment--- is equivalent to allowing no deduction for asset purchase and exempting all interest earnings from tax — the 'tax prepaymet' approach' $(1984, \mathrm{p} 111) .{ }^{10}$

2.2.3 The Blueprints Consumption Tax (BCT): The direct consumption tax actually proposed by the Treasury (1977), and reiterated by Bradford et al (1984) is actually a hybrid scheme that simultaneously calls for cash flow as well as pre-payment treatment depending on the asset characteristics. "It differs from a full-fledged personal cash-flow tax in giving individuals wide latitude to choose between standard and tax-prepayment treatment of savings" (Bradford, 1986, p.90). Indeed some assets such as consumer durables (including owner-occupied housing), for reasons already cited above, are strictly required to follow PPT mode. Over and above the administrative and compliance benefits of pre-payment treatment cited above, the flexibility to choose between CFT and PPT within one tax code, is believed to offer additional advantages. The BCT "allows the taxpayer to smooth the tax liability over time. ... It is needed to avoid making the tax burden depend on the time path of earnings or expenditure" (1986, p. 91). In other words,

\footnotetext{
${ }^{8}$ In most of this paper, and unless made explicit (as in sections 5-6), we shall focus on proportional taxes alone since most analytical results relate to this form taxation.

${ }^{9}$ Elsewhere Ahsan-Tsigaris (1998) have labelled the property such that choice of tax rates renders the mutual budget set equivalence between alternative tax rules as tax rate symmetry.

${ }^{10}$ It is difficult to avoid recognising the fact that the PPT approach described above is essentially a system of lifetime earnings or endowment taxation, pure and simple, a point that has been duly recognised in the early literature (Minarik, 1980, p.310).
} 
if individuals are able to do this averaging right, there will be no need for separate averaging provisions in the tax code. However, we shall return to these administrative matters in section 6 below.

What about the equivalence between a CFT and BCT? For a full discussion of the issues involved, one need to model asset choice, for example, between real and financial ones. If the assets are merely to transfer resources between periods, and if the return on them differs, even if risk is not invoked explicitly, one ends up dealing with alternative views of ex-ante and ex-post equivalence. The latter concepts are better raised when one introduces uncertainty explicitly, and for this reason the relevant discussion is postponed to the next section. Note that the return on any two assets may differ even in the certainty context, say, due to a difference in the holding term. In other words, within the simple two-period model described above, the financial asset may be construed to be a bond whose maturity term is less than that of the real asset, but investors keep compounding the return by keeping it there till retirement. Owner-occupied housing may also be interpreted as the real asset in question. However, the additional complexity that would arise in such a case is that housing services also provide utility, thereby raising the dimensionality of the commodity space. Consequently, the pure consumption allocation model would not suffice as the correct behavioural description.

\subsection{Treatment of Gifts, Bequest and Inheritances}

The Treasury (1977) distinguished between two alternative concepts of consumption (or, income, for that matter). One is the "ability to pay" idea while the second is "standard of living", and opted for the latter definition in its proposals and recommendations. If one went by the ability concept, gifts and bequests received as well as left behind would both be included in the tax base. However, if one switches to the standard of living notion, there arises an asymmetry; gifts and bequest received are clearly part of the consumption tax base, but not when bequeathed (Bradford et al, 1984, p.xvi-xvii). Bradford et al is explicit on this recommendation; "in order to be eligible for the deduction by the donor, all gifts would have to be included in the tax base of the recipient" (p. 123).

Within the standard cash-flow tax, Aaron and Galper (1985) appear to accept the ability notion of consumption, and propose that all (non-charitable) gifts and bequests be treated as consumption by the donor (and hence taxed at source), while recipients also enter the gift and inheritances received in the tax base. In other words, taxes on wealth transfer may be postponed till the inheritances (and returns thereof) are actually consumed. In the absence of multiplicity of assets, it is easy to verify that that the equivalence between CFT and the PPT does indeed go through in such a scenario. Denoting gifts and inheritances received by $I$, and bequests (and gifts) left behind by $B$, the period-by-period constraints in the above model would then be given by

$$
\begin{aligned}
& C_{1}=(Y+I)-S, \\
& \left(C_{2}+B\right)=S(1+r) .
\end{aligned}
$$

Consequently, present value budget constraint becomes:

$$
\left\{C_{1}+\left(C_{2}+B\right)(1+r)^{-1}\right\}=(Y+I) .
$$


The value of the endowment clearly rises by the full value of the inheritance received. Under a full-fledged cash flow tax, this modifies into:

$$
\left(1+t_{c}\right)\left\{C_{1}+\left(C_{2}+B\right)(1+r)^{-1}\right\}=(Y+I) .
$$

Under PPT, likewise, we get,

$$
\left\{C_{1}+\left(C_{2}+B\right)(1+r)^{-1}\right\}=\left(1-t_{E}\right)(Y+I) .
$$

Having interpreted bequests made as consumption by the donor, the CFT tax base in (2.9a) is indeed lifetime consumption, which gross of taxes, equals the full value of the endowment (inclusive of inheritances). Under the PPT, the corresponding tax base is the again the full endowment. Comparing (2.9a) and (2.9b) it is obvious that all it takes is the tax rate symmetry condition for the two budget sets to be equivalent. It also follows that the present value of government revenue also remains intact between the two accounting systems under the same condition on tax rates:

$$
\begin{aligned}
& R_{c}=\left\{t_{c} /\left(1+t_{c}\right)\right\}(Y+I), \text { and }, \\
& R_{E}=t_{E}(Y+I)
\end{aligned}
$$

Turning now to the treasury's (standard of living) interpretation of consumption, under the CFT the taxpayer would be entitled to a deduction for her bequests from the future consumption base:

$$
\begin{aligned}
& \left(1+t_{c}\right) C_{1}=(Y+I)-S, \\
& \left(1+t_{c}\right)\left(C_{2}\right)=S(1+r)-B \\
& \left(1+t_{c}\right)\left\{C_{1}+C_{2}(1+r)^{-1}\right\}=\left[(Y+I)-B(1+r)^{-1}\right] .
\end{aligned}
$$

Or, $\quad(2.11 c)$

Here the lifetime wealth becomes the endowment (inclusive of inheritances) less the amount bequeathed to the posterior generations. As before (i.e., the "ability" measure of consumption), the tax base may still be interpreted as lifetime consumption, but here bequests are not treated as part of the latter. What about the pre-payment tax? The budget equations now modify as follows:

$$
\begin{array}{lll} 
& (2.12 a) & C_{1}=\left(1-t_{E}\right)(Y+I)-S, \\
& (2.12 b) & C_{2}=S(1+r)-B, \\
\text { Or, } & (2.12 c) & \left\{C_{1}+C_{2}(1+r)^{-1}\right\}=\left[\left(1-t_{E}\right)(Y+I)-B(1+r)^{-1}\right] .
\end{array}
$$

Comparing (2.11c) and (2.12c), it is evident that the two budget sets are not equivalent. It is important to note that there are no general rules for setting tax rates that would render these two constraints identical in present value terms. The same remark goes for the present value of government revenue between the two alternative accounting systems. We may summarise the above as follows:

Proposition 2.1 If gifts, bequests and inheritances are allowed in a life cycle saving context, the "standard of living" concept of consumption is inconsistent with the mutual equivalence between the cash-flow and the pre-payment approaches of treating assets acquisition. The "ability to pay" concept however does allow the CFT-PPT equivalence to go through. 
It is intriguing that many authors, while acknowledging the existing ambivalence towards treating bequests as presumed consumption, have nevertheless maintained that the issue has little to do with the choice of the tax base (e.g., Beach et al, 1988, p. 108, Bradford, 1980, p.80). Bradford and Auerbach have more recently remarked that the Blueprints' choice was mainly on administrative grounds whence "there seems to be no compelling $a$ priori theoretical answer to this question" $(2002$, p.17). The issue is important since for many individuals actual lifetime consumption at the time of death would still be short of lifetime income, and unless that is taxed (as presumed consumption by the departed), full taxation of lifetime resources is not attained. In this we reject the dynastic view household treatment. The above analysis clearly shows that over and above equity concerns, the precise manner of treating bequests has an important bearing for the design of the consumption tax. Having made these observations on the treatment of gifts, inheritance and bequests, in any analytical modelling to follow, we shall adopt the ability to pay view of economic quantities, and accordingly interpret any bequest made as presumed consumption in the same period of time. This will be the case even when these conventions are not explicitly recited.

\section{Tax Equivalence in Models of Risk Taking}

In this section we address a number of issues. First we argue that on the subject of equivalence among a set of taxes, the only meaningful comparison is along the ex-ante concept of equivalence, and not ex-post. The latter as we shall see requires highly implausible, and often arbitrary, choice scenarios. Next we re-examine the tax equivalence analysis discussed in the preceding section in a richer context where one has a choice among safe and risky assets. This is done at various levels. A good part of the discussion is carried out where the portfolio choice behaviour is embedded in an inter-temporal savings model that has been widely discussed in the literature. We then take up more complete (and necessarily more complex) choice situations for examination. Indeed the first of two variations of the above is a model where individuals make work-leisure (for a given skill level) as well as the safe-risky asset choice. The last is of risky human capital choice, where the physical investment is restricted to a single non-risky asset. For the purposes of the paper, the models are very general, and the precise choice context is open to wider interpretations than how they are actually phrased.

Notice that once asset choice (between safe and risky) is allowed, the notion of present value of stochastic public revenues or of household budget constraints has to be interpreted accordingly. Here revenue valuation depends crucially on the precise measure of the discount rate that private agents as well as the public authorities use. It turns out that the choice of the discount rate by the public sector is equivalent to a determination of the belief as how it may deal with the risks implicit in tax revenue. Starting with a simple hypothesis where the state is presumed superior to private markets in dealing with risk, we move to one where it is just as able as the private market. And finally, we take up the case where the current revenue risks are dissipated among all future generations to come. Each of these behavioural postulates yields a corresponding risk discount rate. In the process we arrive at a number of rich results. As a byproduct of this analysis, we hope to provide reconciliation among the different results recorded by different authors, which may at first sight appear to contradict each other.

The principal conclusions are as follows. First we establish that the question of tax base equivalence is only meaningful if posed in the ex-ante sense, by which we mean that if two tax 
systems are equivalent they are so for all plausible behavioural rules. Expected present value of public revenue must also be equal between two taxes for the admissible range of behaviour. We then point out that even though the Blueprint's Consumption Tax, as advanced by be US Treasury is meant to be the outcome of a convex combination of cash flow and prepayment accounting devices accorded to different assets, modelled analytically it fails to live up to its name. Given a free rein, it reduces to either a full-fledged CFT or a fullfledged PPT, depending on the precise treatment (i.e., tax prepayment or cash-flow accounting) of the safe versus risky assets elected by the investor!

The discount rate arguments remain controversial, and will probably remain so for a while. Previously Arrow and Lind (1970) provided a careful analysis of why the risk-free rate may indeed be taken as the correct discount rate for the public sector. We offer an additional argument in support of the same view. We stress the plausibility of the state engaging in some degree of risk shifting among generations, including ones yet to be born. In the latter scenario the public risk discount rate may well approximate the risk free rate, a position that is also supported by some preliminary work of an empirical nature on the subject. To the extent these premises are valid, we find that the endowment/earnings tax (hereafter, EET) is not a valid PPT alternative to the CFT. The only scenario where analytically the EET is a genuine equivalent to a cash-flow tax, namely the case of human capital risk, the former cannot be fashioned as a prepayment of future taxes. The simple reason is that risky wages accrue into the future, i.e., after the human capital investment decision has already been made. And there does not appear any plausible mechanism how individuals may prepay tax due on eventual human capital returns. Hence, administratively difficult as it may be, there would seem to be little avenue for implementing a consumption tax except on a cash-flow basis (or via the MPT mode).

\subsection{Ex-ante vs. Ex-post Concepts of Tax Equivalence}

While the dominant criterion of tax equivalence under conditions of certainty is clear-cut, there is no such unique benchmark that is appropriate under conditions of risk and uncertainty. To start with, one needs to make a distinction between the ex-ante and ex-post concepts. How do we go about these definitions? Ahsan and Tsigaris (1998) proposed the following. By exante equivalence of two taxes, one requires that the household budget set, and hence expected utility, be the same between the two tax policies for any plausible decision rule. By contrast the concept of ex-post equivalence may be characterised as a fortuitous event where for a given decision rule, expected utility actually realised by a household happens to be the same for a pair (set) of tax polices in a given state of nature. Note the generality in the first definition in allowing all feasible choice rules, while the ex-post concept is couched in terms of a particular decision rule. In other words, the latter concept allows for the possibility of individuals to achieve an identical indirect utility for a given state of nature even where the budget sets were not identical ex ante. Valuation of government revenue would also have to be identical (again, ex-ante or ex-post, as appropriate) for any two taxes that are presumed equivalent. We believe that the ex-ante concept is the more natural idea for tax equivalence.

Among those proposing alternative definitions, Christiansen (1993) lets the government collect an identical amount of revenue in each state of nature for all tax alternatives. Kaplow (1994), on the other hand, allows the state to actively participate in risk markets much like private agents, and consequently he has more rigid requirements of policies to 
be deemed equivalent. For example, one condition is that the total demand for each asset (combining private and public) remain the same under each policy. We find the latter modalities unnatural and counter to the likely conduct of public policy in an actual context. $^{11}$

\subsection{Ex-Ante Equivalence among CFT, PPT and BCT}

We have already made the point that a full comparison of the Cash-Flow Tax with the Blueprints Consumption Tax requires a model with more than one asset. ${ }^{12}$ Two-period savings-portfolio allocation models just provide one of the simplest means of carrying this analysis forward. Focussing on these three taxes, first we show that analytically a separate and distinct BCT does not survive in asset choice models. The Blueprints Consumption Tax reduces to either a full-fledged CFT or a full-fledged PPT, depending on the treatment (i.e., tax prepayment or cash-flow accounting) of the two assets that is elected by the investor!

Next we turn our attention to the issue of tax equivalence. Indeed this has been the subject of extensive discussion in the literature. Ahsan $(1989,1990)$ had argued that one needed to exempt, under the PPT method, the imputed risk free return on the entire portfolio in order to obtain the equivalence between CFT and PPT. The risk free rate evidently serves as the individual marginal rate of time preference in such a context. In other words, given asset choice one has to modify the pre-payment tax by adding in the excess return (i.e., over and beyond the risk free rate) or, capital gains to the PPT base. We will refer to this new tax as a Modified Prepayment Tax (MPT). ${ }^{13}$ Surely, this does compromise the administrative advantages of the PPT version of consumption taxation in a large way, and we will return to these issues in section 6 below. In effect, therefore, the argument put forward by Ahsan (1990) requires that capital gains or losses receive the same treatment under both cash flow and prepayment versions; they are subject to tax. Ahsan's analysis required that the state use the risk free rate as the correct public discount rate. While the choice of the discount rate is debatable, it sets the stage for subsequent analysis (e.g., see Zodrow, 1995).

We continue to use the familiar two-period life cycle model, with a choice between a safe and a risky asset. No discussion of the preference structure of households is warranted at this stage. ${ }^{14}$ The period-by-period pre-tax budget constraints facing the household born at time-t are given below. ${ }^{15}$

$$
\begin{gathered}
C_{1 t}=Y_{1 t}-\left(a_{1 t}+m_{1 t}\right) ; \\
C_{2 t}=a_{1 t}\left(1+x_{t}\right)+m_{1 t}(1+r),
\end{gathered}
$$

\footnotetext{
${ }^{11}$ For one thing, one does not observe the state to be engaging in portfolio activities required by Kaplow's analysis. Even if one were to allow risk trading by the state, we note that the range of feasible (public) investment strategies may not match the risk characteristics of private behaviour.

${ }^{12}$ While the integration of the BCT concept in the discussion below is a new innovation, otherwise the discussion in sections 3.2-3.4 draws on our previous work, Ahsan and Tsigaris (1998).

${ }^{13}$ Indeed Ahsan had originally labelled it the modified wage tax, but that does not appear to be descriptive of the nature of the tax.

${ }^{14}$ In this paper (i.e., section 3) we do not need to restrict household preferences except that on occasion we require that they be consistent with the postulates of the capital asset-pricing model, and the latter conditions are very general indeed.

${ }^{15}$ The subscript-t refers to the time of birth. Thus $x_{t}$ denotes the random return earned by the t-investor when old.
} 
The notation here is as follows; consumption in each period is denoted by $C_{i t},(i=1,2)$, and $Y$ is the sum of first period income earned by the household by supplying a fixed amount of labour, and gifts and inheritances received, if any. In view of our discussion of section 2 , consumption, unless otherwise stated, would always be interpreted to include any bequests made in the period. Total saving, $S$, takes place via the acquisition of assets. ${ }^{16}$ The amount invested in the risky asset is given by $a$, and that in the safe form by $m$. The rates of return on investment are denoted by $x$ and $r$, respectively, for the risky and the safe asset, with the former taken to be a random variable. When interpreted as financial assets, the institution of limited liability would require that $x$ remain in the interval $[-1, \infty)$.

The lifetime budget constraint of the generation-t investor, in the absence of taxation, is therefore given by:

$$
C_{1 t}+\frac{C_{2 t}}{(1+r)}=\left(Y_{1 t}+\frac{a_{1 t} z_{t}}{(1+r)}\right)
$$

where $z_{t}$ (defined to equal $\left[x_{t}-r\right]$ ) is the excess return on the risky asset over the riskless. The latter quantity may be seen as the result of a change in the risky asset price over the holding period, and consequently, we often refer to the excess return as the capital gain. Evidently, the present discounted value of the consumption stream would be equal to the sum of endowment and the present value of the capital gain.

Taxation: A proportional cash flow consumption tax (CFT), falls both on current (certain) and the second period (uncertain) consumption. With full loss-offset provisions, this tax therefore affects the budget constraint as follows:

$$
C_{1 t}+\frac{C_{2 t}}{(1+r)}=\frac{1}{\left(1+\tau_{c}\right)}\left(Y_{1 t}+\frac{a_{1 t} z_{t}}{(1+r)}\right) .
$$

The full-fledged PPT or, endowment tax, on the other hand, falls only on the endowment, which is certain. ${ }^{17}$ Thus, the resulting constraint is:

$$
C_{1 t}+\frac{C_{2 t}}{(1+r)}=\left(1-\tau_{E}\right) Y_{1 t}+\frac{a_{1 t} z_{t}}{(1+r)}
$$

What about BCT? In spite of the clear definition (i.e., allowing individuals the freedom to choose between the CFT and PPT options for different assets), such hybrid models appear not to have been modelled formally by anyone. Let us elect the safe asset to attract prepayment treatment, while the risky asset receives the cash-flow analysis. Equation (3.1) then modifies into

\footnotetext{
${ }^{16}$ Assets may be either financial or real. While sometimes the financial assets will be interpreted as part of efficient portfolios of households, the case of market incompleteness is not ruled out. Investment in venture capital is also interpretable in the analysis to follow. In the event of real investment, we require that technologies be linear in each, and that one of the two marginal products be stochastic.

${ }^{17}$ Note that an endowment uncertainty would get eliminated through aggregation if this risk were assumed to be of the idiosyncratic variety (Eaton and Rosen, 1980a,b).
} 


$$
\begin{aligned}
& C_{1 t}=\left(Y_{1 t}-a_{1 t}\right)\left(1-\tau_{A}\right)-m_{1 t} ; \\
& C_{2 t}=a_{1 t}\left(1-\tau_{A}\right)\left(1+x_{t}\right)+m_{1 t}(1+r),
\end{aligned}
$$

where we have denoted the relevant tax regime by $\tau_{A}$. Combining these constraints we have

$$
C_{1 t}+\frac{C_{2 t}}{(1+r)}=\left(1-\tau_{A}\right)\left\{Y_{1 t}+\frac{a_{1 t} z_{t}}{(1+r)}\right\}
$$

Comparing (3.5a) and (3.3) we note that these two are exactly the same if the condition of tax rate symmetry holds. What happens if we reverse the roles, namely allow the risky asset to be treated on a prepayment basis, while the safe asset is made subject to the cash-flow rules? The budget equations are now given by (3.6) below, where the tax regime is identified by the rate $\tau_{B}$ :

$$
\begin{gathered}
C_{1 t}=\left(Y_{1 t}-m_{1 t}\right)\left(1-\tau_{B}\right)-a_{1 t} ; \\
\text { (3.6) } C_{2 t}=m_{1 t}(1+r)\left(1-\tau_{B}\right)+a_{1 t}\left(1+x_{t}\right), \\
\text { Or, } \quad C_{1 t}+\frac{C_{2 t}}{(1+r)}=\left(1-\tau_{B}\right) Y_{1 t}+\frac{a_{1 t} z_{t}}{(1+r)} .
\end{gathered}
$$

Lifetime constraint (3.6a) is thus equivalent to (3.4) so long as the two tax rates are the same. We therefore observe that, at least in the portfolio choice context, if the safe asset is elected to attract prepayment treatment, while the risky asset faces the cash-flow analysis, the resulting tax is formally indistinguishable from a full-fledged CFT. Once we reverse the order of asset treatment, namely allowing the risky asset to follow PPT while the safe asset is taxed on a cash-flow basis, we get a full-fledged PPT. The logic is simple; under a cash flow tax, the imputed return on the whole portfolio goes untaxed by virtue of its identification with the required rate of time preference. Analytically therefore a separate BCT does not exist in asset choice models, it reduces to either a CFT or a PPT, depending on the pattern of tax treatment of assets elected by the investor!

The choice of assigning the tax treatment to various assets is done by the individual ex-ante before uncertainty is resolved at the time her decisions are made. The question then is which one, given a safe and a risky asset, would the household select for the prepayment method and which for the CFT in order to maximise expected utility? The precise rule households may follow, given a free choice, would depend on a number of factors. If they are certain to reap a long-term gain (e.g., owner-occupied housing), they may well prefer PPT. Many would prefer a sharing of the risk with the government via the CFT while investing in NASDAQ shares, for example! It may further depend on the investor's perception of how risk is handled by the government. If the belief is such that the government absorbs risk in a costly fashion, much the same as the private sector, then risk considerations are irrelevant to the choice. Thus we differ 
strongly from the suggestion in the Blueprints that the choice of assignment be made primarily on administrative grounds. ${ }^{18} \mathrm{We}$ will soon dwell on the risk disposition issues by the state.

(Ex-Ante) Equivalence: Given asset choice, note that while utility depends on the $\left\{C_{1}, C_{2}\right\}$ distribution, the right hand side (rhs) of the lifetime budget equations as presented above do not uniquely determine the feasible choice set for a given tax regime. The risk-taking variable would generally be a function of the tax regime. Examining equations (3.3) and (3.4) [or, for that matter, equations (3.5a) and (3.6a)], it is clear that so long as both the government and households use the risk-free rate to discount future quantities, PPT and CFT budget sets are not ex-ante equivalent. Taxation of the capital gain term under CFT would affect the choice variables, an element that is absent under the PPT, which effectively continues to be a tax on the lifetime value of the endowment.

What if we include the capital gains component within the pre-payment tax base to obtain the "modified prepayment tax" (MPT) as cited above? For a closer examination, let us write down the MPT budget constraint, where $\tau_{M}$ denotes the tax rate:

$$
C_{1 t}+\frac{C_{2 t}}{(1+r)}=\left(1-\tau_{M}\right)\left[Y_{1 t}+\frac{a_{1 t} z_{t}}{(1+r)}\right],
$$

which is identical to the BCT constraint, (2.5a). Comparing CFT and MPT, it is apparent that neither tax distorts the choice between consuming now and later, but they each distort the choice of the portfolio mix. Clearly the two choice sets [i.e., equations (3.3) and (3.7)] over $\left\{C_{1}, C_{2}\right\}$ would be identical if we set tax rates symmetrically, i.e., set $\tau_{M}=\left[\tau_{c}\left(1+\tau_{c}\right)^{-1}\right]$, and if individual behaviour is such that $\left\{a_{1 t}\left(\tau_{M}\right)\right\}$ were to equal $\left\{a_{1 t}\left(\tau_{c}\right)\right\}$. It may be verified that along a constant expected utility contour (for any quasi-concave function), the latter condition on asset demand is indeed met as shown by Ahsan and Tsigaris (1998, p59). Risky asset demand functions behave as follows:

$$
a_{1 t}\left(\tau_{c}\right)=\left(1+\tau_{c}\right) a(0), \text { and, } \quad a_{1 t}\left(\tau_{M}\right)=\left\{\left(1-\tau_{M}\right)^{-1}\right\} a(0) \text {, }
$$

where $a(0)$ is the pre-tax risky asset optimally chosen by the investor. Thus the tax rate symmetry condition specified above is both necessary and sufficient for the two risk-taking functions to equal each other. However this is along an expected utility contour. Each of these taxes would also induce income effects. It may be further checked that the income effects are such as to require additional compensation of $\left\{\tau_{c} Y\right\}$ and $\left\{\tau_{M} /\left(1-\tau_{M}\right) Y\right\}$, respectively in the two tax situations. Again, the tax rate symmetry is both necessary and sufficient for the income compensation to equal each other (Ahsan and Tsigaris, 1998, p59). Consequently the two budget sets would be identical. Hence we may conclude that the CFT and MPT are ex ante equivalent if and only if the tax rate symmetry condition applies.

The ex-ante tax regime equivalence clearly requires that the government too expect to collect an identical amount of revenue in the two cases for any feasible decision rule. Substituting

${ }^{18}$ Note that we have totally abstracted from liquidity constraints as well as other capital market imperfections. Introduction of liquidity constraints will tilt the preference towards a cash flow consumption tax since the individual can reduce his tax liability under a consumption tax and finance an uncertain lumpy investment. Such an option is not available under the pre-payment approach. See of Atkinson and Stiglitz $(1980, \mathrm{p} 71)$ for related remarks. 
from the household budget constraints, we have the following expressions for government revenue, respectively, for CFT and MPT:

$$
\begin{aligned}
R_{c} & =\frac{\tau_{c}}{\left(1+\tau_{c}\right)}\left[Y_{1 t}+\frac{a_{1 t}\left(\tau_{c}\right) z_{t}}{(1+r)}\right] ; \\
R_{M} & =\tau_{M}\left[Y_{1 t}+\left\{a_{1 t}\left(\tau_{M}\right) z_{t}\right\} /(1+r)\right]
\end{aligned}
$$

In view of the preceding remarks on the optimal risky asset demand induced by the two taxes, it is easy to verify that the revenue constraints would be identical if and only if the tax rate symmetry holds. Indeed, this was the pre-payment method proposed by Ahsan (1989, 1990 a, b), and has been further discussed by Davies (1994). Note that the present result relating CFT and MPT in the asset choice model differs importantly from the parallel relationship between the simple endowment tax and CFT that obtains in a model without uncertainty (as reviewed in section 2 above). In addition to the endowment, the MPT base also includes the eventual capital gains (or, any extraordinary gains over and above the normal return, i.e., the rate of time preference). Hence the MPT base is the lifetime wealth of the household, just as is also the case for the CFT. However the incentive effects turn out to be similar to the certainty case; the household utilities are affected the same way, and the government gets to keep the same expected value of revenue. The time path of revenue again differs between the CFT and MPT, much as under complete certainty. ${ }^{19}$ Introduction of asset choice does not affect these results so long as we ensure the ex-ante budget set equivalence between the two taxes. Note that the above result on the equivalence of the CFT and MPT is independent of the choice of the discount rate; in other words the discount rate may well differ between the private and public sector.

It is interesting to observe that Beach et al (1988) appear to have reached a parallel conclusion even though they did not explicitly consider uncertainty. They warned against a liberal use of the prepayment option, which they argued undermines the consumption tax. "A consumption tax is not equivalent to a tax on labour income, which is what one would have if widespread use of prepayment or exemption method were allowed" (p. 107). They elaborate further: "...[T] he consumption tax is equivalent to a tax on labour income plus profits and economic rents (that is, capital income above and beyond pure interest)... [T] he only component of pure income base that is not taxed under the consumption base is pure real interest which is exactly the compensation that is required by a household for deferring its consumption for a period of time" (emphasis added, p.111). It is also noteworthy that the British tax study of the late 70's led by Lord Meade having recognised the PPT option to CFT, rejected the former whenever the asset in question had the possibility to yield substantial capital gains (1978).

To summarise the above discussion, let us put together the main conclusions as follows.

Proposition 3.1 The Blueprints Consumption Tax is analytically indistinguishable from a full-fledged CFT or a full-fledged PPT. If the household elects to have the safe

\footnotetext{
${ }^{19}$ It is often pointed out that the Government may not be indifferent between different streams of tax revenue with the same present value. Others note that the govt may always meet its constraints by adjusting its borrowing behaviour! We will not get into this debate, as these are not central to the issues at hand.
} 
asset attract prepayment treatment, while the risky asset faces the cash-flow analysis, the resulting tax becomes a full-fledged CFT. Once we reverse the order of asset treatment, namely allowing the risky asset to follow PPT and the safe asset be treated on a cash-flow basis, one ends up with a full-fledged PPT.

Proposition 3.2 (a) The cash-flow tax (CFT) and the simple wage tax (WT) cannot be equivalent in the ex-ante sense so long as households and the government each use the risk-free rate as the discount rate.

(b) The cash-flow tax and the modified prepayment tax (MPT) are ex-ante equivalent if and only if tax rates are symmetric, i.e., $\tau_{M}=\left(\tau_{c} /\left(1+\tau_{c}\right)\right)$. This holds for all possible discount rates, which may well vary between the private sector and the sovereign treasury.

\subsection{The Public Sector Discounting of Risk}

As noted already, Ahsan's results were obtained in a model where the state used the risk free interest rate as the public discount rate, which implies that the public sector is superior to the private market in risk shifting. Risk pooling by the state may be permissible not only because it undertakes heterogeneous (read uncorrelated!) activities, but more along the (second of two!) Arrow-Lind (1970) arguments that the implicit share of each individual in the risk of a given public project is very small. ${ }^{20}$ Ahsan's result has been challenged by Zodrow (1995), who in turn uses the expected weighted average rate (of the safe and risky returns) to discount revenues. The choice of the latter discount rate suggests that the public sector can do no better than the market in spreading risk. Implicit here is the belief that most public projects may be matched with private projects of equal riskiness (Hirshleifer, 1964, 1966, and Sandmo, 1972), a hypothesis, which is essentially empirical in content. We shall return to these issues later in sections 3.4 and 3.5. Zodrow thus finds, much as in one-asset models, that all capital income should be exempted from the prepayment tax base in order to make it equivalent to a consumption tax. Essentially therefore a simple endowment tax continues to serve as a valid pre-payment alternative even under risk. Let us examine the latter finding.

Valuing the CFT Revenue: Here one would use a generic value of the public discount rate, denoted by $\rho$, to rewrite the expected present value of the tax revenue accruing to the state from the cash flow tax:

$$
E\left(R_{c}\right)=t_{c}\left[C_{1 t}+\frac{E\left(C_{2 t}\right)}{(1+\rho)}\right],
$$

Zodrow rewrites the household budget constraint in terms of saving (i.e., the total portfolio, [a $+m]$ ), to obtain

$$
C_{2 t}=\left\{\left(1+t_{c}\right)^{-1}\right\} S_{1 t}\left(\tau_{c}\right)\left\{(1+r)+\beta\left(\tau_{c}\right)(z\}, \text { where } S_{l t}\left(\tau_{c}\right)=\left\{Y_{1 t}-\left(1+t_{c}\right) C_{l t}\right\},\right.
$$

\footnotetext{
${ }^{20}$ Arrow and Lind (1970) argued that the appropriate social discount rate for risky public investment is the risk free rate. This occurs because either (a) the state takes on projects with uncorrelated returns, or, (b) where each project is small in size for the generation of current taxpayers.
} 
where $\beta_{1 t}\left(\tau_{c}\right)$, a measure of proportional risk taking, is defined to be the share of the risky asset in total savings, i.e., $\left\{a\left(\tau_{c}\right) / S\left(\tau_{c}\right)\right\}$.

Substituting the budget constraint (3.10) in (3.9) and simplifying, we have

$$
E\left(R_{c}\right)=\left\{\frac{\tau_{c}}{\left(1+\tau_{c}\right)}\right\} Y_{1 t}\left[1-\frac{S_{1 t}\left(\tau_{c}\right)}{Y_{1 t}}\left(1-\frac{1+r+\beta_{l t}\left(\tau_{c}\right) E(z)}{(1+\rho)}\right)\right],
$$

Note that the revenue function of PPT is risk-free since all of it is received up front thus avoiding the need to discount:

$$
\text { (3.11) } \quad R_{E}=\left(\tau_{E} Y_{1 t}\right) \text {. }
$$

Therefore for the value of CFT revenue to equal that under PPT, we must have:

$$
\tau_{E}^{*}=\frac{\tau_{c}}{\left(1+\tau_{c}\right)}\left[1-\frac{S_{1 t}\left(\tau_{c}\right)}{Y_{1 t}}\left(1-\frac{1+r+\beta_{1 t}\left(\tau_{c}\right) E(z)}{(1+\rho)}\right)\right],
$$

where $\tau_{E}{ }^{*}$ is the required endowment tax rate. Clearly, manipulating tax rates alone will not guarantee the above condition to be met. What about a judicious choice of the discount rate? Indeed, if the public discount rate, $\rho$, is set equal to the weighted average market return, $\left[r+\beta_{1 t}\left(\tau_{c}\right) E(z)\right]$, both methods yield an identical present value tax revenue. This is essentially Zodrow's rebuttal to the earlier results by Ahsan $(1989,1990)$. Zodrow's argument that an endowment tax is a valid prepayment alternative to the cash flow tax is exclusively based on the above discount rate argument. The major shortcoming of using the weighted average as the discount rate is that the weight, namely the proportion of saving allocated to the risky asset, is an endogenous variable depending on the tax regime as well as the tax rate itself, and one that would not be known a-priori. In other words, it would require the public authorities to possess information that may be costly to obtain. ${ }^{21}$ A further remark would be that the above construction relied upon a restatement of the household budget, namely the expression for future consumption cited above (eq. 3.10). Here it would seem that one is unwittingly letting foregone consumption valued by consumer at the rate $\{(1+r)+\beta z\}$, which is not in the spirit of Fisherian intertemporal economics. Zodrow defends the above hypothesis on the public discount rate by citing that it is consistent with the government bearing the full costs of risk bearing, but no attempt is made to model the latter. A simple introduction in this direction is provided in the next section, where we obtain more durable results.

Valuation of the MWT Revenue: Before leaving the discounting methodology, we may wonder if one may use a parallel argument as above to obtain possible ex-post equivalence between PPT and MPT. Proceeding as above, the present value of MPT revenue is:

\footnotetext{
${ }^{21}$ Bradford has argued that the PPT and CFT differences are cosmetic, and uses an illustration to support the viewpoint. The illustration builds on the familiar Domar-Musgrave phenomenon which posits that, given full loss offsets, individuals may be able nullify the effects of the tax by a suitable choice of risk taking so as to obtain the pre-tax consumption (see eq 3.8 above). The risk sharing argument goes through whenever the state shares in the risky gains. CFT does induce this effect, but this is only the substitution effect of the tax. The Bradford example therefore does hold in the absence of the income effect.
} 


$$
E\left(R_{M t}\right)=\tau_{M}\left[Y_{l t}+\frac{a_{l t}\left(\tau_{M}\right) E(z)}{(1+\rho)}\right] .
$$

Comparing (3.11) and (3.13), it is clear that for any finite value of $\rho$, we do not have ex-ante equivalence. Insofar as ex-post considerations are concerned, one can always compute wage tax rates that satisfy the revenue constraints, but these do not appear to be interpretable, and hence are devoid of policy implications. ${ }^{22}$ The important point is that there is no ex-ante equivalence as we have conceived the term.

In conclusion we note that the possible ex-post equivalence between PPT and CFT argued by Zodrow contrasts with the result between CFT and MPT discussed in Section 3.2 above. Not only does the previous result, namely proposition 3.2(b), holds ex-ante, it does so for any feasible choice of the discount rate either by households or by the state, and the rates chosen by the two parties need not coincide.

To sum up the discount rate approach to tax equivalence, we state the following:

Proposition 3.3 (a) The search for a social discount rate does not yield ex-ante equivalence either between $\{C F T$ and PPT\} or between $\{P P T$ and MPT\}.

(b) However were the social discount rate to equal the weighted average rate of return on assets, then a cash flow consumption tax would be equivalent to an endowment tax, albeit in the ex-post sense. A similar search for a discount rate for the equivalence between PPT and MPT appears to be futile.

\subsection{Arbitrary vs. Endogenous Choice of the Public Discount rate}

The results cited above derive different conclusions while each adopting a different hypothesis on the magnitude of the exogenously given discount rate. Is the choice of the discount rate a matter of taste? Use of the certainty equivalence approach may lead to further insights. Ahsan and Tsigaris (1998) argue that in order to reach more definitive results, it is necessary to describe a behavioural model of risk disposition by the government. The certainty equivalent, namely the expected value less the risk premium, then becomes the effective budget constraint for the government. One major advantage of this approach is that it endogenises the choice of the discount rate. We may start by assuming that the government returns lump sum to each household the lifetime revenue as taken from the same household. Taxpayers would then value the stochastic transfer by evaluating the latter's market certainty equivalent. The market value may be computed by invoking the capital asset pricing model (CAPM). It then follows that in such a context for individuals who hold fully diversified market portfolios, the certainty equivalent of the additional revenue in question is then precisely zero. Investors in effect equate the expected extra-ordinary gain from risky investment to its risk premium. Indeed authors such as Bulow and Summers (1984), Hamilton (1987), Auerbach (1991), and Bradford and Auerbach (2002) have argued along these lines. Individuals then would remain indifferent between a consumption tax and an endowment tax. .

One may criticise the implicit assumption of perfect markets and fully diversified household portfolios; however, Ahsan and Tsigaris (1998) adopt an analytical perspective. They observe

\footnotetext{
${ }^{22}$ Indeed a tax rate, $\tau_{E}{ }^{*}$ set equal to $\left(\tau_{M}\left[1+\left\{\alpha\left(\tau_{M}\right) E(z) /(1+\rho)\right\}\right]\right)$, where $\alpha\left(\tau_{M}\right)$ is the share of the endowment allocated to the risky asset, would do.
} 
that governments typically undertake intergenerational risk sharing, and wonder if this may lead to a more efficient risk shifting in the overall economy. The state's ability to pre-commit a generation to engage in such risk sharing with future generations had been earlier recognised in the public economics literature (e.g., Gordon (1985), Gordon and Varian (1988)). ${ }^{23}$ Thus when there is an unlucky (lucky) outcome, the latter's distribution being assumed independent through time, the government can create (retire) public debt. The burden of debt (joys of debt relief) can be passed on to all future generations even though it was incurred by the current unlucky (lucky) generation. It is intuitive that efficient allocation would call for each future generation to bear a small share in the risks of today's lottery.

We are then confronted with an environment where investors only bear the net-of-tax fraction of the risk; the balance is passed on to future, as yet unborn, generations through the intermediation of the government. In exchange, the current generation also shoulders a share of the risky tax revenue collected from past generations of taxpayers. Thus each generation receives as transfer a composite portfolio of current and past lotteries. The model leads to a continuum of discount rates depending on the extent of intergenerational risk sharing. If none, we are back to the Bulow-Summers-Hamilton-Zodrow world. If the number of generations were many, the social discount rate converges to the risk-free rate. Clearly in this case the systematic risk facing a given generation becomes idiosyncratic when it is shared with many future generations. Indeed it turns out that to the extent there is some revenue sharing across generations, the household utility is higher under the consumption tax (or the MPT) than under the simple endowment tax à la Zodrow. Here the CAPM is retained to evaluate the certainty equivalent of the public transfer. Below we merely cite the main findings, while the reader is referred to the original paper for the derivation (Ahsan-Tsigaris, 1998). However a brief outline of the model is presented in a short appendix at the end of the paper.

Proposition 3.4. (a) Even if households held the market portfolio, intergenerational risk sharing leads to a positive market valuation of the risky tax revenue.

Proposition 3.4(b): The public discount rate becomes finite, and monotonically decreases as the number of intergenerational risk sharers increases.

Proposition 3.4(c): The social discount rate would equal the risk free rate when all future unborn generations bear a small share of the "market" risks of today's lottery.

Before leaving this section we should reiterate that the above rehabilitation of the risk free rate as the correct social discount rate under uncertainty arises exclusively out of the ability of the state to shift risk across generations. If this is Pareto improving, as has been argued above, there is no reason why this should not be done, and hence such risk sharing is a predictable behaviour for all rational legislatures. However, note that this is distinct from the risk-shifting that occurs in the Arrow-Lind model. The latter authors argued that "a public investment can be considered as an investment in which each individual taxpayer has a very small share" (1970, p370). Consequently, "the government distributes the risk associated with an investment among a very large number of people.... It is the risk-spreading aspect that is

\footnotetext{
${ }^{23}$ Intergenerational risk sharing would not hold in a model where the household has an infinite horizon as in Hamilton (1987). In fact, Hamilton's model is akin to a world where households exhibit altruism towards future generations.
} 
essential to the result" (p366). To sum up then, the central Arrow-Lind argument in support of the risk free rate as the social discount rate is based on the state being able to apportion the risk of each uncorrelated project among a large number of risk sharers. In contrast, proposition 3.4 is obtained in a context where the revenue payable by each generation may well be (fully) correlated with the market portfolio, but they are uncorrelated in time. And, hence it is suitable to engage in risk-shifting across all future generations.

\subsection{Measuring the Risk Discount Rate: An Aside}

The discussion of sections 3.3 and 3.4 suggest that what is crucial for the correctness of the risk free rate as the social discount rate is the mutual independence of investment returns. How plausible is this empirically? Arrow-Lind themselves raised the concern: "if there is positive correlation between the returns of an investment and other components of national income, the question remains whether this correlation is so high as to invalidate the previous result" (p373). Sandmo also wondered on the relevance of an ideal stock market (for each state-time contingencies) and real world markets: "How close the approximation may be is of course an empirical question..."(p 296).

Ahsan and Tsigaris (2002) develop a framework to measure the closeness of the returns from public investment with the components of GDP, and thereby attempt an answer to the above debate. Neither Arrow-Lind nor Hirshleifer-Sandmo actually dwell on how one may be able to empirically verify the issue at hand. Clearly one would first require an observable equivalent of the benefits of public investment. Arrow and Lind make the important point that benefits of public investment may in general accrue both to private agents (e.g., farmers gaining from public investment in irrigation) and to the government. The former would be valued by private individuals "with respect to both time and risk in accordance with the preferences of the individuals to whom they accrue" (p377). The social discount rate therefore applies only to the benefits that accrue to the government. In their exact formulation, however, the government actually "captures all benefits and pay all costs" (p370), since private individuals who gain from the investment are presumed to pass on the benefit to the treasury in entirety.

Our first observation is that the above description hints at how one may go about measuring the public gains from public investment. The most direct manner we know how "the beneficiaries pay to the government an amount equal to the benefit received" is via the institution of taxation (whether construed as Lindahl prices or otherwise). It is therefore proposed that public investment (say, in education, health, and infrastructure) lead to gains in the productivity of labour and capital. Given a well functioning tax system, such private sector gains would lead to higher government revenue on account of augmented wages, profits, and value of transactions. Thus tax revenue would serve as the observational equivalent of the public gains. Evidently not all revenue arises out of enhanced productivity due to investments in public education and health; but the procedure proposed by Ahsan and Tsigaris (2002) use tax revenue flows only to measure its volatility relative to GDP.

The underlying framework is one where public investment is bond financed, while the debt charges are covered by taxation. Consequently, the discount rate is derived implicitly as the rate that value-maximising investors are willing to pay for government bonds that are earmarked to be serviced by future taxation. Thus a test of the extent of the co-variability between the return from public investment and GDP then simplifies to one between 
government revenue flows and GDP. While specific revenue components (e.g., on corporate profits) may be highly correlated with the market, for investment in public goods, however, it is the aggregate revenue that ought to matter. ${ }^{24}$ And at that level the relevant risk premium is seen to be fairly small in absolute terms. The gap between the (real) risk free rate and the risk adjusted social discount rate for total revenue is about two percentage points (2.6 vs. 5.1, respectively, for the US data, 1950-2000). Another way of looking at that statistic is to reflect that the risk adjusted public discount rates cited above turns out to be a mere fraction (half or even less) of the rate applicable to private projects of average risk (i.e., equal to market). The latter figure is about 9.0 percent.

Consequently, Ahsan-Tsigaris (2002) conclude that use of the risk free rate, as the correct risk discount rate for public sector investment, would involve only a minor error. The intuition here is that the portfolio of assets embedded in the state's revenue claims provides additional diversification than is available through financial markets. Therefore, even investors holding well-diversified stock portfolios may legitimately view claims on state revenue as vehicles for further risk shifting.

\subsection{Labour Supply in a Model of Capital Risk}

Everyone agrees that among the most basic decisions households must make within a lifecycle context are the choice of work-leisure (during working life), consumption allocation over time (namely, the saving decision), and the allocation of savings among assets of various riskiness. Of course, even prior to the leisure decision comes the human capital/occupational choice. However it would be too ambitious to deal, at least in the analytical context, with all four decisions simultaneously! However a simple model with three of the four elements appears tractable (Ahsan, 1991). This model allows leisure choice in period-1 only, where the individual is presumably retired in the second period, but may receive a transfer, $Y_{2 t}$ (e.g., an un-funded state pension). The individual is assumed to posses an initial quantity of non-human wealth $(A)$, which when added to the value of human endowment $\left(w L_{0_{t}}\right)$, yields full income, which we denote by $Y_{l t}$ (i.e., $Y_{l t}=A+w L_{0 t}$ ). It is seen that allowing utility to be derived from leisure makes important differences in the saving/risk-taking decisions, a linkage that is lost in a pure consumption allocation context.

Considering an earnings-cum-endowment tax (EET), future consumption would be given by the following:

$$
\text { (3.15a) } \quad C_{2 t}=\left\{\left(1-t_{E}\right)\left[Y_{2 t}+(1+r)\left(Y_{1 t}-C_{1 t}-w\left(L_{0 t}-L_{1 t}\right)\right)\right]\right\}+a_{1 t} z
$$

where $L_{l t}$ is of course the total units of labour supplied. The rest of the notation is similar to the models analysed above. The above may be rearranged to render a more familiar form:

$$
\text { (3.15b) } C_{1 t}+(1+r)^{-1} C_{2 t}=\left(1-t_{E}\right)\left[Y_{1 t}+(1+r)^{-1} Y_{2 t}-w\left(L_{0 t}-L_{1 t}\right)\right]+(1+r)^{-1} a_{1 t} z \text {. }
$$

This then is the prepayment tax in this framework, where the second period transfer is merely a matter of detail, and does not detract from the integrity of the PPT method of accounting for asset acquisition whatsoever.

A cash-flow tax, on the other hand, would include eventual excess return as above:

\footnotetext{
${ }^{24}$ Recall that the Bulow-Summers argument for a zero certainty equivalent actually referred to corporate capital gains.
} 


$$
C_{1 t}+(1+r)^{-1} C_{2 t}=\left(1+t_{c}\right)^{-1}\left\{Y_{1 t}+(1+r)^{-1} Y_{2 t}-w\left(L_{0 t}-L_{1 t}\right)+(1+r)^{-1} a_{1 t} z\right\} \text {. }
$$

Comparing (3.15b) and (3.16) makes it obvious that the issues of tax equivalence (ex-ante or ex-post) here are exactly the same as found in models of asset allocation without the leisure dimension. We therefore find no new results to report here, although the incentive and efficiency effects of taxation differ between the two models, as we shall review in section 4 below.

\subsection{Human Capital Risks and Savings}

Now we focus on the fourth decision element cited above, but drop the choice among assets. Here risky wages accrue in period-2, while the human capital investment decision is made in the prior period, i.e., if we restrict ourselves to a two-period framework. We observe immediately that, unless we include the initial endowment and all subsequent transfers that individuals receive in the earning/endowment tax base, the former is not equivalent to a cash-flow tax. Let us examine a simple model briefly.

The model reviewed here is analogous to that originally proposed by Levhari and Weiss (1974) although they did not study the issues of taxation. They developed a two-period Fisherian model where future wages are stochastic and conditional on the investment in human capital. This model is rather similar to that used for analysing the portfolio-savings choice under uncertainty (sections 3.2-3.5). One major difference from the latter is that the return to human capital is conditional on the amount of human capital investment (as well as depending on the state of the world). Endowed with exogenous ("full") income $Y_{l t}$, the individual allocates the latter to current consumption $C_{l t}$, and investment in non-human $\left(K_{l t}\right)$ and human capital $\left(w H_{l t}\right)$ in the first period. Presently we denote the total time endowment by $H_{0 t}$ (instead of $L_{0 t}$ as in the preceding section) in order to have a consistent but easily distinguishable notation among different models.

Letting $w$ be the wage rate per unit of time and $H_{1 t}$ the amount of time spent on human capital acquisition, the foregone earnings in the first period is $w H_{l t}$. The latter quantity is therefore taken as the magnitude of investment in human capital. More formally the first period constraint is given by:

$$
\begin{gathered}
C_{l t}=A+w\left(H_{0 t}-H_{l t}\right)-K_{l t} \\
\text { Or, }\left\{K_{l t}+w H_{l t}\right\}=\left(A+w H_{0 t}\right)-C_{l t}=Y_{l t}-C_{l t} \equiv S_{l t},
\end{gathered}
$$

where as in the preceding section, $Y_{l t}=\left\{A+w H_{0 t}\right\}$. Clearly we identify the left-hand side of the last expression as total savings. This shows that the individual has basically two investment choices through which she can transfer consumption into the future. She can allocate $S$ between non-human capital $\left(K_{l t}\right)$, and her investment in foregone current earnings in the amount $w H_{l t}$ (which is limited to a maximum of $w H_{0 t}$ ). In the second period the individual earns a return from the investment in human capital, denoted by $f\left(\mu, H_{l t}\right)=\mu F\left(H_{l t}\right)$, where $F\left(H_{l t}\right)$ is the known human capital production function, with standard properties namely, positive but diminishing marginal returns, i.e., $F_{H}>0$ and $F_{H H}<0$, respectively. The variable $\mu$ represents the random element entering the wage profile in a multiplicative way, which is further structured to lie in the closed interval $[\omega, \varpi]$ with mean $E(\mu)$. Following Levhari and Weiss, we take the random variable as affecting future earnings and marginal returns positively. The latter assumption implies a 
positive correlation between marginal and average rate of return to human capital. The positive correlation in turn implies that as time allocated to human capital increases, the variance of future earnings also increases, namely the principle of increasing risk. ${ }^{25}$

It is useful here to also allow for a future exogenous income $\left(Y_{2 t}\right)$. Proceeds for future consumption $\left(C_{2 t}\right)$ may thus be obtained, in addition to human capital returns, from nonhuman capital investments, $K_{1 t}(1+r)$, where $r$ is the certain rate of return and the transfer $\left(Y_{2 t}\right)$. The second period constraint is given by: $C_{2 t}=\left\{Y_{2 t}+\mu F\left(H_{1 t}\right)+(1+r) K_{1 t}\right\}$.

We find it convenient to write out the expression for future consumption more explicitly as follows:

$$
\text { (3.17a) } \quad C_{2 t}=Y_{2 t}+(1+r)\left(Y_{1 t}-w H_{1 t}-C_{1 t}\right)+\mu F\left(H_{1 t}\right)
$$

which may be alternatively written as

$$
C_{1 t}+\frac{C_{2 t}}{(1+r)}=Y_{1 t}+\frac{Y_{2 t}}{(1+r)}+\frac{\mu F\left(H_{1 t}\right)}{(1+r)}-w H_{1 t}
$$

The above formulation may be easily related to the standard asset allocation model studied in section 3.2-3-4 above by simply restating (3.17b):

$$
C_{1 t}+\frac{C_{2 t}}{(1+r)}=Y_{1 t}+\frac{Y_{2 t}}{(1+r)}+\frac{\left(x_{x}\left(\mu, H_{1 t}\right)-r\right) w H_{1 t}}{(1+r)}
$$

where $x_{t}\left(\mu, H_{1 t}\right)=\frac{\mu F\left(H_{1 t}\right)-w H_{1 t}}{w H_{1 t}}$ is the random rate of return from the investment in human capital. The inter-temporal budget constraint in (3.17c) indicates that the present value of the consumption stream is equal to the present value of the endowment stream plus the present value of the excess return from human capital investment discounted at the risk free rate. The excess return in this "portfolio choice" model is $x(\mu, H)-r=\frac{\mu F(H)-w H_{1 t}}{w H_{1 t}}-r$. The difference from the asset choice behaviour analysed above of course is that the rate of return from the investment in human capital depends on the amount invested in the risky asset.

A Tax on Earnings: A simple earnings tax affects the budget as follows. Future consumption now modifies into:

$$
C_{1 t}+\frac{C_{2 t}}{(1+r)}=A+\frac{Y_{2 t}}{(1+r)}+\left(1-t_{E}\right)\left(\frac{\mu F\left(H_{1 t}\right)}{(1+r)}+w\left(H_{0}-H_{1 t}\right)\right)
$$

\footnotetext{
${ }^{25}$ Levhari and Weiss (pp953-55) provide details of these findings for the model where earnings are given by a general function, $f(\mu, H)$, even though much of their comparative static analysis relies on the multiplicative form. For simplicity we directly focus with the multiplicative form, i.e., $f=\mu F(H)$, which calls for some conceptual changes. In particular, presently $F_{H}>0$ is sufficient for $f_{\mu H}$ to be positive (and thus for the principle of increasing risk to obtain).
} 
Even if the earnings tax (in common with the cash-flow tax) reduces the foregone earnings and future rewards from human capital investment proportionately, it is important to recognise that the tax does reduce the variance (and, indeed all higher moments) of investment returns more than proportionately. Consequently this feature of proportional taxation makes human capital more attractive on the margin relative to physical savings for a risk averse individual. As seen above such distortions are totally absent either in a certainty framework, or in models of portfolio risks.

A Cash-Flow Tax: The inter-temporal budget constraint is now given by:

$$
C_{1 t}+\frac{C_{2 t}}{(1+r)}=\frac{1}{\left(1+t_{C}\right)}\left(Y_{1 t}+\frac{Y_{2 t}}{(1+r)}+\left(\frac{\mu F\left(H_{1 t}\right)}{(1+r)}-w H_{1 t}\right)\right)
$$

While, neither tax distorts the relative price of current and future consumption, it is obvious that unless the endowment and other transfers are included in the endowment/earnings tax base, the two are not equivalent. With the EET so amended, note that the distinction made previously between the modified prepayment tax (MPT) and the EET disappears totally. The risky income component enters into both tax bases, and therefore none of the related debate on the wage tax vs. cash flow tax encountered previously arises here. Moreover, presently there is a strong reason for the state to use the risk free rate as the social discount rate to value future revenue as human capital risks are believed to be largely uncorrelated across individuals. ${ }^{26}$

Unfortunately however, there is no real possibility here of a conceptual analogue of a prepayment tax! Would one be willing to argue that we allow individuals to finance their education and training in a totally private system (i.e., with no state subsidies), and as a reward, they would not be required to file any income tax ever again on future risky earnings? The standard wage tax as studied above, essentially subsidises the training by lowering the net post-training returns, and if we truly adopted the prepayment option for this investment, we would be denying this subsidy. In that case, there would be no labour income taxation whatsoever! Other examples are equally facetious. If the interpretation is to impose a tax on training costs (as a prepayment) in lieu of no future taxes, we run into similar obstacles. How is one to value the training costs of Bill Gates' apprenticeship in someone's garage!

Returning to the model discussed above, there is at least one scenario where the dominant risk would be that of human capital. Interestingly, this situation would arise if household portfolios were believed to be fully diversified, and consequently one fully equated the excess return (over and beyond the risk free rate) as risk premium. In that event, the one physical asset as modelled above may not be a very bad approximation. In such a world of risky human capital, one may legitimately use the endowment-cum-wage tax in lieu of a cash-flow tax, as both are equivalent.

Proposition 3.5 (a) In a world of human capital risks, the earnings tax base has to be expanded to fully tax the initial endowment and all transfers, and hence obtain

\footnotetext{
${ }^{26}$ Elsewhere Ahsan and Tsigaris (2001) carry out a more complete analysis of the effects of various taxes in the human capital risk model described above.
} 
the earnings-cum-endowment tax (EET). The latter is indeed equivalent to a cashflow tax.

(b) However, the equivalent EET may not be fashioned as a prepayment tax since all risky wages accrue after the human capital decision has already been made.

\subsection{A Post-script on the Ex-Ante vs. Ex-Post Equivalence}

Legal scholars such as Graetz (1980) and Warren (1980) have taken issue with the Treasury's original proposal to allow individuals a relatively free choice of the PPT and CFT accounting privileges as to asset allocation on the premise that the lifetime budget sets were equivalent ex-ante in both these cases. These authors wondered: "is equal present value an acceptable basis for assessing tax?" (Graetz, p.170). Of course Graetz is referring to the fact that present value of lifetime consumption equals the post tax value of the initial endowment both under PPT and CFT. As has been discussed above, the particular result Graetz cited obtains only when no formal account is taken of asset diversification. However the language chosen to put forward their views gives an impression as if the logic of "expected present value" is somehow the culprit.

The preceding discussion (especially sections 3.3-3.5) makes it amply clear that the devil is in the choice of the discount rate one uses to compute present value of revenue flows over time, and not in the idea of PV constraints at all. If we believed in intergenerational risk shifting (or, indeed if the conditions of the Arrow-Lind theorem held fully), to reiterate points already made, we may easily accept the risk free rate as the correct social discount rate. And in such a context the present value of budget constraints are very different between CFT and PPT! Put differently, once we recognise that lifetime present value of consumption in an asset choice world sums to the endowment plus the expected capital gain (loss) on the investment, the wage tax is no longer the relevant substitute for consumption taxation. Additionally, the important point is that individuals do not have the option to prepay the tax due on the expected capital gains, an idea full of conceptual and practical difficulties. If the cash flow mode is chosen, the tax is due when the asset return has just been realised and thus available for consumption (or bequest). If the MPT is the chosen accounting framework, having already prepaid tax on the endowment in period-1, individuals are still obliged to file a tax return in period-2 for the capital gain (loss) component. And indeed, if a loss has occurred, the person would claim back some of the pre-paid tax depending on the loss-offset rules in force. Given that individuals would on average expect to make a positive gain, they each expect to pay a further tax on realisation. Thus if we accept the modified prepayment tax as proposed above, the difficulties that Graetz and other have noted about treatment of lucky and unlucky investors melt away.

The legal discussion also puts a lot of store in the timing of events, and prefers to measure things historically rather than in the expected sense. But our discussion clarifies that a coherent ex-ante concept of tax base equivalence can be phrased in the expected present value sense, and is superior to the conceivable ex-post (which we find to a large extent arbitrary) concept as argued above. The MPT, which we have argued to provide ex-ante equivalence with CFT, does tax individuals correctly over time even though we have fully accepted the present value criterion in our deliberations. 


\section{Efficiency Issues in the Design of the Consumption Tax}

Most discussion of the efficiency and incentive effects of the choice of PPT vs. CFT has been in the areas of policy guidelines typically related to specific treatment of assets (e.g., housing). In this section we shall briefly review a selective numbers such policy issues as well as keeping a focus on the alalytics at issue.

\subsection{Asset Specific Issues}

Asset Arbitrage Games: Bradford cites the administrative difficulties in monitoring all disposal of assets as a prime reason for allowing the pre-payment option. One immediate consequence would be that individuals would strategically choose which assets to declare in qualified accounts (and take a deduction for current saving) and for which to pre-pay the current tax in lieu of no further taxation on the return thereafter. Presumably, depending on the individual's risk aversion, riskier assets would be preferred for the cash-flow treatment, while more secure ones (e.g., real estate and other long-term investments) would be chosen for the pre-payment route. It is widely believed that assets such as real estate may be very risky over the short term (both in terms of resale value as well as in terms of the carrying costs, chiefly mortgage interest), but rather secure (and high yielding) if held for several decades. Depending on the loss-offset provisions of the tax code, which is fairly generous in most OECD countries, the state (under the BCT) may end up sharing in the gains and losses of household investments, which are both riskier, and one that is possibly of shorter duration vis-à-vis the broader portfolio. (Note that the pre-payment option would encourage profit taking on short-term capital gains.) This is clearly anomalous from the points of view of allocative efficiency in that the tax code provides different incentives in the choice of assets than investors would make in the absence of public interventions. ${ }^{27}$ A full-fledged cash flow tax would overcome this anomaly. We shall return to administrative and compliance issue related to measurement of returns later.

We should reiterate that the above asset arbitrage issues might be present even when one does not directly consider models of subjective uncertainty. For example, an examination of the term-structure of asset holding would also indicate a room for arbitrage opportunities. Indeed Arnold Harberger, without focussing on risks directly, had observed that "any taxpayer would be able to reduce his tax by electing prepayment on investments with expected high rates of return, while using the cash flow method for investments with low rates of return" (1980, p119).

(b) Household Durables: In several related writings, Bradford suggested that the PPT treatment apply to all consumer durables including owner-occupied housing even within an otherwise cash-flow version of the consumption tax. "This means no deduction for the purchase of the asset and no inclusion of any value of the return from the asset, whether in real services or in cash flow upon sale" (Bradford, 1986, p85). The idea behind the proposal is that such an asset "provide most of its yield in the form of direct consumption services" (1980, p85), and hence by pre-paying the tax, the household has already pre-

${ }^{27}$ The related equity implications are discussed in the section that follows. 
paid the tax due on the flow of consumption services. ${ }^{28}$ Indeed by allowing the prepayment option to all financial investments, the latter scheme does appear to offer a level playing field. However, contrasting assets held in a qualified account (as in the CFT) with the PPT treatment of owner occupied housing does create much of the allocative effects we identified above under "asset arbitrage". Since typically people hold on to owner occupied housing for a long time, thus rendering the investment rather secure, and one that has historically appreciated in value over time, obliging tax payers to use the PPT route would encourage them to consume too much housing than otherwise. The capital gains upon disposal would go entirely free in this scheme. The thrust of our arguments in section 3 above would lead one to keep the final capital gain in the tax base for all appreciable assets held outside of qualified accounts in order to avoid this anomaly, no matter how messy this might be. In other words, opt for the MPT scheme rather than the PPT in the case of owner-occupied housing. We would of course propose that full inflation accounting be accorded to such capital gains (i.e., indeed for assets held outside of QAs). It is perhaps curious that Canadians have sort of enjoyed a quasi QA status for owner occupied housing. Years ago, one could save a limited amount of funds each year in a dedicated account (registered homeownership plan, RHOSP), and no taxes were imposed on the eventual purchase of a home. This may be interpreted as saying that the housing equity kept enjoying (at least the fraction so financed) the qualified status. However, depending on the capital gain rules (which have changed frequently since), this scheme may also be termed as merely a direct subsidy to encourage the housing industry. Presently, though RHOSPs are no more, investors may still finance the home purchase from the proceeds of a registered pension savings (a qualified account), and not lose the qualified status in the process. The latter possibility has been available for quite some time.

For the remainder of household durables, such as automobiles and domestic appliances and the like, we believe that the Bradford suggestion of equating the current outlay as correctly valuing the future flow of services is a good and practicable one. Note that these are all depreciable assets, while owner occupied housing is quite to the contrary, and hence the separate treatment.

\subsection{Analytical Arguments}

Here the key issue pertains to the determination of the true risk shifting capacity of a modern state (say in a mature economy setting). If the state has no such ability, the efficiency and incentive implications are simple; the differences between the PPT and CFT (at least in models of financial asset diversification) are largely cosmetic. The PPT becomes a mere tax on earnings. The higher savings under the equivalent CFT is illusory as the extra amount is designed to finance taxes on future spending. Higher risk-taking, also induced by CFT, likewise is a mere attempt to retain the pre-tax distribution of future consumption unchanged (absent income effects). These points have been well analysed in the literature cited in section 3 above.

\footnotetext{
${ }^{28}$ For this to hold exactly, it must be noted that both the magnitude of the actual flow of future services as well as the economic value of the services would have to be known in advance with certainty (Beach et al, 1988, p107).
} 
However, to the extent one endows the state with a positive role in further risk shifting (as the reading of the literature would nudge us in that direction), it is the modified prepayment tax which leads to cosmetic differences vis-à-vis the cash-flow tax. The PPT, a tax on earnings and endowment (EET), has very different properties. Let us cite two specific results that we think are potentially important. We first pick one that departs from the confines of the pure saving-asset allocation models, while the second belongs to the more standard framework.

The Leisure Model: Ahsan (1991) pointed out that once a third good, namely leisure is allowed (see section 3.6), we have interesting outcomes. Notably, wages being common to all three tax bases (i.e., PPT, CFT and MPT), increased taxation leads to additional leisure being consumed in all cases. Hence for expected utility to remain constant, both current and future consumption happen to decline. Consequently in this context, ignoring income effects, it is seen that the utility compensated effects of PPT and the CFT are very different. ${ }^{29}$ While the earnings tax in the standard asset choice model leaves both risktaking and saving unaffected (e.g., Ahsan, 1990a), once choice of leisure is an additional factor, both these incentives are hurt by the same tax. These are seen as consequences of having to lower future consumption to accommodate additional leisure in the three good model. In contrast, while generally ambiguous, both CFT and MPT does stimulate risk taking for plausible parameter values in the case of constant relative risk aversion (CRRA) preferences. A similar conclusion holds for the saving incentive in the case of CFT. While the saving behaviour is (now only partly) stimulated by CFT on account of future taxes on consumption, MPT leads to a discouragement (and here one need not invoke the CRRA restriction).

Inter-Generational Risk Shifting: The case of intergenerational risk shifting, as we noted in section 3.3, provides perhaps the strongest analytical support for the belief in state's ability to shift private risks. In terms of efficiency of alternative taxes, here it is seen that a cash flow (or equivalently an MPT) consumption tax would typically lead to a Pareto improvement in the risk allocation vis-à-vis the simple earnings tax. As noted above, individuals evaluate public transfer of risky revenue, which is a composite portfolio of current and past revenue histories, behind the Rawlsian veil of ignorance, i.e., at the time of the enactment of the tax/transfer policy. Since the revenue attributable to each generation is identically distributed through time, the transfer scheme proposed above does not affect the expected value of the composite lottery at all. However it is seen that the optimal weights assigned to each generation's experience, leads to a lowering of all higher moments vis-à-vis similar aspects of any given generation's own revenue. Thus steady state expected utility would be increased under the proposed transfer scheme. ${ }^{30}$ The earnings tax, alas, has no such beneficial transfer scheme to fall back on!

Returning to the work-leisure behaviour, we note that under the prepayment tax approach, the distortions caused in labour-leisure and asset choices will lead to welfare

\footnotetext{
${ }^{29}$ The incentive effects of taxation may be discussed at several levels. The benchmark of constant expected utility typically yields sharper results, and that is the only reason for the focus here.

${ }^{30}$ This is strictly true in the steady state. Out of steady state (i.e., during transition to the new scheme), say the currently old generations may be no worse off vis-à-vis the status quo. But all intermediate generations are strictly better off even in non-steady state. See Ahsan-Tsigaris (1998), and the brief appendix at the end of this paper.
} 
losses, and thus the task of finding an optimal pre-payment wage tax rate can only be obtained in a second best world. In the presence of lump sum taxation the optimal prepayment wage tax would be zero as long as the endowment or wage rate of the individual is certain. In the case of imposing a cash flow or the equivalent modified pre-payment tax, and under the assumption that the risk-bearing costs to the state is lower than the market, there is an optimal CFT or MPT. ${ }^{31}$ One example evidently is where the state engages in intergenerational risk sharing. The optimal CFT/MPT may be obtained regardless of whether there is labour income uncertainty, so long there is a lump sum tax/transfer available. This would also be the case if the risk premium were to fall with the imposition of the tax as Gordon (1985) has argued would happen under intergenerational risk sharing.

To sum up the above discussion we may highlight the following.

Proposition 4.1 (a) Unfettered access to the choice of asset treatment may lead to an unbalanced portfolio of assets whose risk the state has to share via the lossoffset provisions within the CFT, namely assets which are, on average, both riskier and of shorter maturity;

(b) Strict prepayment provisions assigned to owner-occupied housing may distort the choice of assets (i.e., within an otherwise CFT mode) by encouraging individuals to demand too much housing;

(c) In the context of inter-generational risk shifting, a cash flow tax (or equivalently, an MPT) leads to a Pareto improvement allocation of welfare vis-à-vis the endowment tax of the PPT mode.

\section{The Equity Dimension}

\subsection{Defining Equity}

It is the ex-ante view of equity advocated by the Blueprints that has drawn a lot of criticism. It is clear that the desire to retain the prepayment option of implementing the consumption tax necessitates the so-called ex-ante view, namely that the potential choices rather than actual choices made by households matter. The underlying scenario has been that for any two individuals with an identical exogenous endowment, the choice set is identical, circumscribed only by the size of the endowment. One may save a lot or little, and the same goes for the instruments of saving (so long as these are all market instruments). Bradford has defended the Blueprints position for the ex-ante concept, and has stressed that income opportunities are a better basis for taxation than actual outcomes. Once in the PPT mode, "receipt of interest, receipt of dividends, and asset purchases and sales, have no consequences for the tax base" (Bradford, 1886, p93). We do note that a certain ambivalence about a wholehearted acceptance of the ex-ante approach to equity existed in the original Blueprints. Indeed it was thought to be a "...major disadvantage ... that .. lucky investors might become very rich and owe no additional tax liability on future consumption of their wealth. Conversely, unlucky investors will have prepaid a tax on expected returns

\footnotetext{
${ }^{31}$ The optimal tax is obtained by balancing the marginal welfare loss due to the disincentive effects of the tax in terms of distorting the agents' decisions and the marginal welfare gain that is associated by having the state absorb risks at a lower costs through intergenerational risk sharing.
} 
and will then obtain no deduction for the losses they incur" $(1977,129)$. It is on these grounds that it is often alleged that the election of the pre-payment method would induce 'horizontal inequities' in the presence of uncertainty, since those with a high realised return will benefit and those faring worse would remain worse off. ${ }^{32}$

Question then arises: what is the right principle of fairness in taxation? It is common to find people agreeing on a measure of "lifetime resources" as a yardstick by which to measure wellbeing. However that again begs the question, ex-ante or ex-post? A casual look at the Rawls criterion would suggest it is the ranking of the eventual outcome of the process (e.g. economic game) that matters. However, his preferred mode of attack would appear to be to narrow the eventual differences in outcomes by a suitable restructuring of the rules (i.e., write a proper constitution). Otherwise there would be no great concern to invoke the veil of ignorance. In short we argue here that that when it comes to equity one must deal with both the ex-ante as well as ex-post fairness, not one at the expense of the other. Given the possible dichotomy between the two, and hence the concern with the issue in the first place, the ex-post ranking is perhaps to be accorded immediate priority. That does not mean that we do not level the playing field. The latter, other things equal is expected to lead to lesser of a problem with ex-post inequities down the road. While we do not wish to over-extend the analogy, the differences between the two concepts are to an extent, comparable to the complementarity between preventive and remedial measures. Even if best practice preventive measure were adopted, (and thus by analogy, ex-ante opportunities had been "equalised"), it is still conceivable that unacceptable outbreaks (results) would still emerge, and they indeed do, which would require urgent attention.

Thus the position taken in this paper differs only slightly from the arguments advanced by authors who have typically stressed the ex-post version. To quote Graetz, "regardless of the precise form of the definition of income or consumption, horizontal equity must be an expost concept. Circumstances should be considered as similar only after results are known; lucky gamblers are not the same as unlucky gamblers" (1980, p171). He actually cited Kaldor (1955, pp60-64) for supporting a similar position. Much in the same spirit, Warren declares that to treat all with equal endowments equally, as is implied by the exante notion of equity, "....is irrelevant in discussion of fairness, which should turn on outcomes rather than expectations" (1980, p.121).

In so far as vertical equity goes, Graetz continues to argue that "..if one accepts a vertical equity criterion that relates the distribution of tax burden to 'ability to pay', ex post rather than ex ante circumstances are relevant" (p171). And, "with a progressive rate structure, the cash flow version of the tax would narrow the after-tax differences between the lucky and unlucky investor in ways that the .. alternative would not" (p173). We may add that earlier in the paper we also have endorsed the ability to pay notion as a measuring guide in place of the standard of living for otherwise the lifetime resources are not fully accounted for (section2.3).

\footnotetext{
${ }^{32}$ The second edition of the Blueprints appears to be more accommodating; "this possibility could be largely avoided, at a price in complexity and compliance costs, by taxing the future returns on some or all investments that are not made through qualified accounts, or by restricting the types of investment that could be made outside of qualified accounts" (1984, p125).
} 


\subsection{Consumption Tax Design and Equity}

While we have endorsed the concept of ex-ante equivalence in choosing between tax bases, this is in no conflict with our concern for ex-post outcomes. Recall that our modified prepayment tax has been argued to be fully equivalent to the cash flow tax in all the behavioural settings we have examined. To an extent, this is a manifestation of the usefulness of the keeping the complementarity between the two concepts in perspective. Davies (1994) has examined the MPT in some detail. He notes that a cash-flow consumption tax (or, an MPT) gives both ex ante and ex post equity since tax burdens under each are proportional to expected and actual consumption. Thus MPT and CFT would each be consistent with the requirement of both horizontal and vertical equity. The simple earnings tax, however, would not. Horizontal equity is ensured by the fact that under MPT or CFT, households who are identical ex-ante also fare identically ex-post; while not so with EET, except in the model with risky human capital (section 3.6). As already seen, the earnings-endowment tax is fully equivalent in the latter model to a CFT, and both satisfy the requirements of ex ante and ex-post equity.

Vertical equity may also be guaranteed by replacing the proportional consumption tax (either CFT, MPT, or EET, as the case be) by a linearly progressive schedule. It may be verified that the analysis presented above would also go through in the latter case. The difficulties regarding ex-post equity under a wage tax get exacerbated in a world of unequal initial endowment. Those with the larger endowment may turn out to be plungers, and depending on the state of nature, may lose pretty much everything. Hence ranking of post-tax realised lifetime wealth would be reversed from the pre-tax distribution.

Davies further notes that MPT also relates to the proposals made by the Queen's University economists in Canada to tax business income on a cash-flow basis. As discussed in Boadway and Bruce (1984) and Boadway, Bruce, and Mintz (1984), cashflow business taxes are equivalent to taxes on pure economic profit or "rent" (i.e., on above-normal returns). Thus, for non-corporate business income, the modified prepayment status can be achieved simply by taxing business income on a cash-flow basis under the personal tax base. If a corporate income tax is retained, and is implemented in a cash-flow form, then integration may be achieved by adding in corporate source income only under the direct tax base.

\subsection{Transaction specific Issues}

Gifts, Bequests and Inheritances: The Blueprints' preference for adopting the standard of living measure of consumption is widely seen as leading to a serious erosion of wealth equity. Wealthy families would be able to transfer vast amounts of wealth from one generation to another with little taxation in the process. Bradford et al recognises that a switch to the ability concept would take care of this shortcoming (Bradford et al, 1984, p 125). Some have argued that since both the donor and the donee derive utility from the transfer of wealth, it is proper to tax both (Minarik, 1980, p307). Pechman has gone on to propose an additional instrument to deal with the problem: "To prevent excessive concentration of wealth, the expenditure tax would have to be accompanied by high death and gift taxes" (Pechman, 1983, p203). We have seen that adoption of the ability concept is necessary in measuring consumption otherwise one does not fully measure lifetime resources when gifts and bequests are involved. This concept requires that both gifts 
received as well as bequests left behind be in the tax base (preposition 2.1). It has been shown there that even in the absence of risk and uncertainty, the budget set equivalence between CFT and PPT does not go through unless taxes extend to gifts and bequests simultaneously. Thus there is no great hurry to enact new estate tax laws, mere consistent application of the consumption tax principles would do.

Durables and Housing: The treatment of housing as proposed by BCT, over and above, inducing allocative distortions as note above, would also lead to growing inequity of wealth. By letting the capital gains on owner occupied housing tax-free would help wealthy families to deepen asset inequity. The ex ante neutral treatment of owners and renters, or among taxpayers who purchase a home at different points in their career, does little to ameliorate the ex-post differences due to unforeseen price changes, financing costs, and the like. ${ }^{33}$ Here our suggestion has been stated many times above; we require such gains to be in the tax base under the MPT banner. To us housing gains are no different from any other above normal returns.

\section{Issues of Measurement, Administration and Compliance}

Since the paper has focussed only on analytical issues, the administrative aspect that we go into are those that are direct ramifications of what has been presented above, namely the analysis of sections 2 and 3. Therefore we can be very brief here, and selectively so. The major point we wish to make is that the our results yield suggestions for reforming the design of the consumption tax that would make it more politically appealing, and thereby improve the chances of its legislative passage. We make this argument in several stages.

The principal issue as we see is how to overcome the administrative inconvenience of MPT. The convenience of the simple pre-payment option as construed in the Blueprints was a major argument in favour of the consumption tax. With the required accounting for above normal gains and such, this simplicity is gone. Zodrow goes farther. He argues that accounting for capital gains would make the MPT more complicated than the CFT. Indeed he fears that the ensuing complications may preclude a direct consumption tax altogether (1995, p.259). We believe that such pessimism is uncalled for, and suggest that the changes proposed below would go a long way towards political and broader social appeal.

(a) Political Expediency may dictate that the CFT or MPT version be endorsed instead of the original PPT à la Blueprints. Brown has argued "it is essential to add lifetime savings to the tax base in some way if the consumption tax is to get much public support" (1980, p116). Here by "lifetime savings" he clearly means the realised value of lifetime savings, much of which will go untaxed if one opted for the prepayment option to holding assets as the Blueprints Consumption Tax had recommended. Thus we claim that MPT is a serious contender here.

(b) Ability to pay concept ought to be adopted in dealing with gifts and bequests even on administrative grounds. Recall that earlier we have endorsed this position on both

\footnotetext{
${ }^{33}$ Brown also cites these problems (1980, pp 114-115). Graetz (1980) also holds views similar to that of the present authors.
} 
analytical as well as equity grounds. One administrative difficulty that arises with the "standard living" definition of consumption is that for either the PPT or BCT scheme, if the bequest is left by a deceased from a non-qualified account, the decedent would in principle be entitled to a refund (on the "prepaid tax"). Problems may arise in that the estate may lack any positive tax due against which to use the above deduction. Indeed, the Blueprints' authors prefer to deal with this issue by proposing a separate wealth transfer tax rather than forego the principle of standard of living measures. "Under this option, all features of the Cash Flow Tax would remain exactly as explained as above, except for the wealth transfer tax. Tax rates on gifts and inheritances could be designed to achieve any desired degree of equalisation in initial wealth of individuals." (Bradford, et al, 1984, p125).

We find this particularly intriguing. It is no denying that the BCT, by allowing liberal use of pre-payment option to asset acquisition, is designed so that administrative advantages are strong vis-à-vis the income tax. But by proposing an extra layer of taxation with none of the difficulties of measuring capital gains and the like lessened in the process, seems to be an about face. By contrast the ability view of consumption avoids these complexities of separate tax schemes by simply treating bequests as presumptive consumption. Brown also appears to endorse the ability measure, which in effect renders "the wealth tax an integral part of the consumption tax design (1980, p.116). We agree fully.

(c) Limit choice of assets allowable for prepayment: Our results suggest that if we give the investor the freedom to choose how they want to have various assets treated under consumption taxation, the prepayment option is correct only for govt bonds, including those issued by municipal as well as state governments. On housing, the initial purchase should clearly continue to be treated post-tax (i.e., no deduction), but final capital gains ought to be taxed for analytical and equity reasons (i.e., the MPT status).

(d) Averaging and the time Path of Tax Payments: Bradford (1986) points out that a virtue of Blueprints version of the consumption tax is that by allowing a free mix of cash flow and pre-payment treatment of assets, one achieves averaging of tax payments over time. Otherwise one would have to take recourse to an additional mechanism to allow the averaging of payments between periods. Clearly the issue is more significant the more progressive is the tax structure. ${ }^{34}$ To us the self-averaging suggested by Bradford may not be practicable by all; to effectively use the two methods of accounting for asset acquisition and disposal would require careful tax planning, and many would not succeed unaided by professional help. There is also the issue of future evolution of the tax structure; conceivably tax rates may move up or down over time (say, depending on macro fundamentals), and therefore the averaging foreseen by taxpayers would eventually fail to accomplish the desired uniformity in the consumption plans by averaging the period by period tax payments. For all these reasons, an automatic averaging schemes may have to be implemented anyway (as is currently done under income tax in many countries, including Canada). ${ }^{35}$ Therefore we conclude that the averaging argument need not stand in the way of implementing the CFT or the MPT!

\footnotetext{
${ }^{34}$ Since consumption over time is less volatile than income, Beach et al suggest that the issue of averaging is less severe in the case of consumption tax than under the income tax $(1988, \mathrm{p} .107)$.

${ }^{35}$ Taxpayers do not even have to ask for this privilege; the revenue administration authorities may do this routine calculation for all tax filers.
} 


\section{Conclusion}

We hope to have established a number of results and clarified several outstanding issues in the design of the consumption tax. Note that the results we get do not all come from the risk models. Even in the pure certainty framework, we find that the standard PPTCFT equivalence does not go through unless one adopts the "ability to pay" view of economic magnitudes (rather than the "standard of living") especially when gifts and inheritances are involved. In risk models we see that ex-ante tax equivalence (defined to mean equivalence between tax regimes that hold for all plausible behavioural rules) does not hold between CFT and PPT, instead between CFT and MPT. The alternate notion of ex-post equivalence (necessarily holding true for specific behavioural instances) may hold between CFT and PPT, but these we characterise as being fortuitous. The only event where a full-fledged EET turns out to be ex-ante equivalent to CFT occurs in a model of risky human capital. But here the former cannot be dubbed a pre-payment tax in any sense of the term since the risky earnings occur after the investment (often, long after) has already been made. Another result of interest arises in the context of intergenerational risk shifting. We find that a cash flow tax (or equivalently, an MPT) leads to a Pareto improvement in the allocation of welfare vis-à-vis the earnings/endowment tax of the PPT mode.

In the equity area, we argue that our analytical perspective suggests that the debate in the literature on ex-ante vs. ex-post equity is a bit misplaced. Both notions of equity are indispensable for credible conduct of public policy, as these are complementary. Both the process as well as the outcome needs to be judged fair in order to achieve overall fairness. Achieving equitable outcome, the focus of most writings, would be hard without an equitable process that allows equal access to all.

Finally we offer the insights from our analytical tour to suggest reforms for the consumption tax design on order to improve its political as well as wider social appeal. We find that adding extraordinary gains made on investment under the purview of consumption tax, allowing a full accounting of gifts and bequests, and limiting the number of assets that may be allowed to be treated on a strictly prepayment basis, we may succeed in selling the consumption tax idea better. 
Appendix on Intergenerational Risk Sharing: The discussion below relates to the model described in section 3.4, where there is no work-leisure or human capital choice, only the choice of investments. We assume that all generations ( $n$ in number) share in the current "market" risk via a stochastic tax policy. If the government absorbed some of the risk onto the budget through taxation, the relevant market valuation of tax revenue applies to the stochastic transfer that the individuals get from the government's intergenerational risk sharing arrangement at time- $t$ as shown below. ${ }^{36}$

$$
A_{t}=\sum_{i=0}^{n-1} \gamma_{i} T_{z(t-i)},
$$

where $\gamma_{i}$ is the weight of each lottery that is allocated to the generation born $i$-periods later, and $T_{z(t-i)}$ is the tax revenue from the excess return realised by the $(t-i)$-generation. ${ }^{37}$ We model the optimal choice of the weights attached to each generation's revenue experience such that the outcome is endogenous. In other words, we do not, by design preclude a scheme of no risk sharing arrangement (as implicit in Summers and Bulow (1984), Hamilton (1987), Zodrow (1995)). If the latter event were to occur, the chosen weights would be $\gamma_{0}=1$ and $\gamma_{j}$ $=0$ for all $j=1$ to $(n-1)$, and then we would have the equivalence between PPT and CFT. However, below we show that these weights would not be optimal, and hence a pre-payment wage tax without the inclusion of financial risk cannot be viewed as equivalent to the CFT.

We will let a social planner decide on the optimal weights and once this has been done, the transfer (or the public good) available at time- $t$ to the currently young steady state generation would depend on the certainty equivalent value of the revenue stream $A_{t}$. Clearly the weights of all generations would have to sum to unity: $\sum_{i=0}^{n-1} \gamma_{i}=1$. Furthermore, to illustrate how the government can spread the risk across generations, let us consider three generations sharing their financial risks through the tax system as set out in the schema given below.

Table 1: Three Generations Sharing Systematic Risk through the Tax System.

(Time of tax/transfer policy enactment $t=0$ )

\begin{tabular}{||l|l|l|l|l|l||}
\hline \hline & $t=0$ & $t=1$ & $t=2$ & $t=3$ & $t=4$ \\
\hline Allocation of risky tax payment of the old at $t=0$ & $\gamma_{0} T_{z 0}$ & $\gamma_{1} T_{z 0}$ & $\gamma_{2} T_{z 0}$ & & \\
\hline Allocation of risky tax payment of the old at $t=1$ & & $\gamma_{0} T_{z 1}$ & $\gamma_{1} T_{z 1}$ & $\gamma_{2} T_{z 1}$ & \\
\hline Allocation of risky tax payment of the old at $t=2$ & & & $\gamma_{0} T_{z 2}$ & $\gamma_{1} T_{z 2}$ & $\gamma_{2} T_{z 2}$ \\
\hline Allocation of risky tax payment of the old at $t=3$ & & & & $\gamma_{0} T_{z 3}$ & $\gamma_{1} T_{z 3}$ \\
\hline Allocation of risky tax payment of the old at $t=4$ & & & & & $\gamma_{0} T_{z 4}$ \\
\hline
\end{tabular}

Each row in Table 1 indicates the spreading of an old generation's risky revenue across time to yet unborn generations. For example, the currently old (first row) receive only a fraction of their own tax payment: $\gamma_{0} T_{z 0}$. The rest of the tax payment is transferred onto time periods, $t=1$, and $t=2$. Clearly, each row adds up to the gross tax payment by the relevant generation, and each generation gets as a transfer, stochastic in nature, as the sum of each column. The transfer is to be evaluated in an ex ante manner, before uncertainty is resolved, i.e., at the time of the enactment of the tax system. ${ }^{38}$

\footnotetext{
${ }^{36}$ By the steady state generation we mean that it shares in $(n-1)$ previous risks in addition to a fraction of its own risk.

${ }^{37}$ Since endowment income is certain we have removed it from the above evaluation in order to focus on the inclusion or exclusion of the excess return component.

${ }^{38} \mathrm{We}$ are assuming that the economy is operating at the golden rule of capital accumulation, and hence the interest rate is equal to the growth rate of population. In this case the horizontal row will add up the individual's tax payment. Thus we are assuming a steady state with no loss or gain to society from the spreading of tax revenue. This is Gordon and Varian's (1988) base case. If the economy does not operate at
} 
A social planner chooses the appropriate weights $\gamma_{i}$ by minimising the variance of the public provision:

$$
\operatorname{Minimize} L=\operatorname{Var}\left(\sum_{i=0}^{n-1} \gamma_{i} T_{z t-i}\right)+\lambda\left(1-\sum_{i=0}^{n-1} \gamma_{i}\right)
$$

The solution is such that $\gamma_{i}=(1 / n)$, i.e., it is optimal for each generation to share equally. ${ }^{39}$ Thus the expected value of the MPT revenue attributable to the t-generation is as follows:

$$
E\left(A_{t}\right)=E\left[\sum_{i=0}^{n-1} \gamma_{i} T_{M t-i}\right]=E\left(T_{M t}\right)
$$

How would the market price the above revenue? Using CAPM, we obtain the following certainty equivalent:

$$
C E\left(T_{M, t}\right)=E\left[\sum_{i=0}^{n-1} \gamma_{i} T_{M, t-i}\right]-\lambda \operatorname{cov}\left[\sum_{i=0}^{n-1} \gamma_{i} T_{M, t-i}, r_{m, t+1}\right]
$$

Expanding terms and using the properties of covariance we get:

$$
C E\left(T_{M, t}\right)=E\left(T_{M, t}\right)-\lambda \operatorname{cov}\left[\gamma_{0} T_{M, t}+\gamma_{1} T_{M, t-1}+\gamma_{2} T_{M, t-2}+\ldots, r_{m t+1}\right]
$$

Given the presumption of social risks across generations being idiosyncratic, i.e.,

$$
\operatorname{cov}\left[\gamma_{i} T_{M, t-i}, r_{m t+1}\right]=0, \quad \forall i \neq 0,
$$

the covariance of $T_{M, t}$ is the only relevant term in the above evaluation. Hence:

$$
C E\left(T_{M, t}\right)=E\left(T_{M, t}\right)-\lambda \operatorname{cov}\left(\gamma_{0} T_{M, t}, r_{m t+1}\right) .
$$

Correspondingly, the value of "risky" tax revenue would be higher than in a world of no sharing of generational risks. Even assuming that the household held the market portfolio, the valuation is:

$$
C E\left(T_{M, t}\right)=\tau_{M}\left[Y_{1 t}+\left(1-\gamma_{0}\right) \frac{a_{1 t}\left(\tau_{M}\right) E(z)}{(1+r)}\right] .
$$

Thus as long as there is some intergenerational risk sharing, (i.e., the current steady state generation gets only a fraction of its own risk back, $\gamma_{0}<1$ ), the certainty equivalent of the tax revenue will be higher

the golden rule of capital accumulation, the social planner will still choose some risk sharing to occur. (See Gordon and Varian for other special cases).

${ }^{39}$ Any type of risk-averse function would result in the same outcome as long as it is consistent with the capital asset pricing model. We also assume that the variance of the stochastic transfer remains constant over time. 
relative to the value in the absence of risk sharing as seen above. The public discount rate for the evaluation of risky tax revenue (denoted by $\rho$ in the text) implicit in the present derivation is given by: ${ }^{40}$

$$
\rho=\left[\frac{(1+r)}{\left(1-\gamma_{0}\right)}-1\right]
$$

One case is of special interest, and this occurs as $\gamma_{0}$ approaches zero. In other words, the discount rate would approach the risk free rate as the number of unborn generations sharing in the current "social" risks is large. Efficient risk allocation would thus require that each generation bear only an arbitrarily small share in the risks of today's lottery. The certainty equivalent of the MPT revenue would in the latter event become:

$$
C E\left(T_{M t}\right)=R_{M t}=\tau_{M}\left[Y_{1 t}+\frac{a_{1 t}\left(\tau_{M}\right) E(z)}{(1+r)}\right]
$$

Consequently, the tax revenue risk becomes idiosyncratic. The capital asset pricing model fails to set a zero market value to the stochastic transfer because such a security is not traded in the financial market. Gordon and Varian state why the private market fails to risk share risks across generations:

"Later generations cannot participate in the securities market for lotteries which occur before they are born because they are not alive ex ante to buy shares in these lotteries. An agent cannot profitably buy shares on behalf of later generations since there would be no legal mechanism to force these later generations to accept any losses, implying that the agent would have no incentive to pass on any gains. The problem is that later generations cannot pre-commit themselves to participate in a lottery even when they would gain in expected utility by doing so. By the time they can commit themselves, they know the outcome. These problems arise when two generations are not both active in the securities market before the outcome of a particular lottery is revealed, even if their lives do overlap at some point.

The Government, however, could well have the power to commit later generations to share in the outcome of earlier lotteries. If so there is a potential for Pareto-improving policies which share the risks between generations."

A family may also attempt a similar risk sharing arrangement. However, in the latter event, this is compromised by the non-existence of a legal mechanism to require the subsequent generations to accept the outcome (e.g., past losses).

Note that a curious case for redistribution is already built-in via the consumption tax design under the generational sharing scheme. Lump-sum transfers of the type discussed above will be directed even to an individual who has not invested in risky assets, which may well include a majority of the less well off in society. Consumption taxation may then serve to redistribute income, and at the same time reduce the portfolio risk of the diversified individual, and hence, make all individuals better off in the process.

\footnotetext{
${ }^{40}$ This is obtained by setting the present value of the risky tax revenue using the certainty equivalent method equal to the present value of the tax revenue using the discounting method, and solving for the required rate of return.
} 


\section{References}

Aaron, H. A. and H. Galper, (1985), Assessing Tax Reform, (Washington, DC: Brookings Institution).

Ahsan, S. M., (1989), "Choice of Tax Base under Uncertainty: Consumption or Income?" J of Public Economics, 40, 99-134.

-----, (1990a), "Risk-Taking, Savings and Taxation: A re-examination of Theory and Policy", Canadian J of Economics, 23(2), 408-33.

-----, (1990b), “Consumption and Income Taxation: Horizontal Equity and Life Cycle Issues: Comments", in Rose, M, Ed., (1990a), ibid., 109-115.

, (1991), “Tax Policy in a Model of Leisure, Savings, and Asset Behaviour”, CES Working Paper Series, No. 7, August.

Ahsan, S. M. and P. Tsigaris, (1998), "The Design of a Consumption Tax under capital Risk", Journal of Economics / Zeitschrift für Nationalökonomie, 68(1), 53-78.

Ahsan, S. M. and P. Tsigaris, (2001) "Taxation and Human Capital Accumulation", CESifo Public Economics Conference, Munich (www.CESifo.de)

Ahsan, S. M. and P. Tsigaris, (2002), "Measuring the Social Discount Rate under Uncertainty: A Methodology and Application", CESifo Working Paper No. 824 (December).

Arrow, K. J. and R. C. Lind, (1970), "Uncertainty and the Evaluation of Public Investment Decisions", American Economic Review, 60, 364-78.

Atkinson, A. B. and J. E. Stiglitz, (1980), Lectures on Public Economics (New York: McGraw-Hill).

Auerbach, A. J., (1991), "Retrospective Capital Gains Taxation", American Economic Review, 99, 263-86.

Auerbach, A. J. and D. F. Bradford, (2002) "Generlaized Cash-Flow Taxation”, mimeo, Princeton University, September.

Barro, R., (1979), "On the Determination of the Public Debt”, J of Political Economy, 87, 940-71.

Beach, C, R. Boadway and N. Bruce (1988) Taxation and Savings in Canada, Ottawa: Economic Council of Canada.

Boadway, R., and N. Bruce (1984), "A General Proposition on the Design of a Neutral Business Tax", J of Public Economics, 24, 231-39.

Boadway, R., N. Bruce, and J. Mintz, (1984), "Taxation, Inflation, and the Effective Tax Rate on Capital in Canada", Canadian Journal of Economics, 17(1), 62-79.

Bradford, D. F. (1980), “The Case for a Personal Consumption Tax”, in: Pechman, J., ed., ibid, 75-113.

Bradford, D. F. (1986), untangling the Income Tax, Harvard University Press, Cambridge, Mass.

Bradford, D. F., and the US Treasury Tax Policy Staff (1984), Blueprints for Basic Tax Reform, $2^{\text {nd }}$ ed. (Washington, DC: Tax Analysts).

Brown, E.C. (1980), Comments, in: Pechman, J. ed., ibid, 113-117.

Bulow, J. I., and L. H. Summers, (1984), "Taxation of Risky Assets", J of Political Economy, 92, $20-39$.

Christiansen, V, (1993), "A Normative Analysis of Capital Income Taxes in the Presence of Aggregate Risk", Geneva Papers on Risk and Insurance Theory, 18, 55-76.

Davies, J. B., (1994), "Equity and the Tax Mix: Theoretical Perspectives", in A. Maslove, Ed, Issues in the Taxation of Individuals (Toronto: Univ. of Toronto Press). Eaton, J. and H. S. Rosen, (1980a), "Taxation, Human Capital, and Uncertainty", American Economic Review, 70(4), 705-15.

Eaton, J. and H.S. Rosen, (1980a), "Labour Supply, Uncertainty, and Efficient Taxation," Journal of Public Economics, 14, 365-374. 
Eaton, J. and H. Rosen, (1980b), "Taxation, Human Capital, and Uncertainty," American Economic Review, 70 (4), 705-715.

Goode, R (1964), The Individual Income Tax, (Brookings Institution, Washington, DC).

Gordon, R. H., (1985), "Taxation of Corporate Capital Income: Tax Revenues versus Tax Distortions", Quarterly J of Economics, 100 (1), 1-27.

Gordon, R. H., and H. R. Varian, (1988), "Intergenerational Risk Sharing", J of Public Economics, 37, $185-202$.

Graetz, M., (1980), “Expenditure Tax Design”, in: Pechman, J., ed., ibid, 161-276.

Haig, R. M. (1921), "The Concept of Income- Economic and Legal Aspects” in Haig, R. M. Ed., The Federal Income Tax (NY: Columbia University Press), 1-21.

Hamilton, J.H., (1987), "Taxation, Savings, and Portfolio Choice in a Continuous Time Model," Public Finance, 42 (2), 264-282.

Harberger, A. (1980), Comments, in: Pechman, J. ed., ibid, 117-120.

Hirshleifer, J., (1964) "Efficient Allocation of Capital in an Uncertain World," American Economic Review, 7785.

Hirshleifer, J., (1966), "Investment Decisions under Uncertainty: Applications of the State Preference Approach", Quarterly J of Economics, 60, 252-77.

IFS (Institute for Fiscal Studies) (1978), The Structure and Reform of Direct Taxation, (London: Allen and Unwin).

Kaplow, L., (1994), "Taxation and Risk-Taking: A General Equilibrium Perspective", National Tax Journal, 47(4), 789-98.

Kotlikoff, L. J., (1993), "From Deficit Delusion to the Fiscal Balance Rule: Looking for an Economically Meaningful Way to Assess Fiscal Policy", Zeitschrift für Nationalökonomie, Supplement 7, 17-41.

Lintner, J., (1965), "The Valuation of Risk Assets and the Selection of Risky Investments in Stock Portfolios and Capital Budgets", Review of Economics and Statistics, 47, 13-37.

Mayshar, J., (1977), "Should the Government Subsidise Risky Projects?” American Economic Review, 67, $20-28$.

Merton, R. (1983), "On the Role of Social Security as a Means for Efficient Risk Sharing in an Economy Where Human Capital is not tradable" in: Zvi Bodie and John Shoven, Eds. Financial Aspects of the United States Pension System, University of Chicago Press.

Minarik, J. A. (1980), “Conference Discussion”, in: Pechman, J. ed., ibid, 297-323.

Pechman, J. A. (1980), What Should Be Taxed: Income or Expenditure?” The Brookings Institution, Washington, DC.

Pechman, J. A. (1983), Federal Tax Policy, $4^{\text {th }}$ edition, (Brookings Institution), The Brookings Institution, Washington, DC.

Richter, W., (1993), "Intergenerational Risk Sharing and Social Security in an Economy with Land", Zeitschrift für Nationalökonomie, Suppl.7, 91-103.

Richter, W., and W. Wiegard, (1991, "On the Difference between Income and Consumption Taxes when the Return to Savings is Uncertain", Recherche Economiques de Louvain, 57, 379-390.

Rose, M., (1990a), Heidelberg Congress on Taxing Consumption, Berlin: Springer-Verlag.

Rose, M., (1990b), “The Superiority of the Consumption Tax System”, in Rose M. Ed. (1990a), ibid.

Rose, M., (1998), "Tax Reform in Transition Economies: Experiences from the Croatian Tax Reform Process of the 1990s", in: P. B Sorensen (Ed), Public Finance in a Changing World, Houndmills, 257-278.

Rose, M., (1999), "Recommendation on Taxing Income for Countries in Transition to Market Economies", in: M. Rose (Ed), Tax Reform for Countries in Transition to Market Economies, Baden-Baden, 23-62. 
Samuelson, P.A. (1964), "Principles of Efficiency: Discussion," American Economic Review, P\&P, 54, 93-96.

Sandmo, A., (1972), "Discount Rates for Public Investment under Uncertainty", International Economic Review, 13, 287-302.

Sandmo, A., 1985, The effects of taxation on savings and risk-taking, in: A.J. Auerbach and M. S. Feldstein, eds., Handbook of public economics, Vol. I (North-Holland, Amsterdam).

Schumpeter, J: A. (1929/30), “Öokomnomie unde Soziologie der Einkommeenstreuer, Der Deutsche Volkswirt, Bd. 4, 380-85. (reprinted in: W: F: Stolper and Chr. Seidl, Eds, Joseph A. Schumpeter, Aufsätze zur Wirtschaftspolitik, Tuebingen: J.C. B. Mohr (Paul Seibeck), 85-103.

Sharpe, W. F., (1964), "Capital Asset Prices: A Theory of Market Equilibrium under Conditions of Risk", J of Finance, 19, 425-42.

Summers, L. H., (1981), "Capital Taxation and Accumulation in a Life Cycle Growth Model", American Economic Review, 71(4), 533-45.

US Department of the Treasury, (1977), Blueprints for Basic Tax Reform (Washington, DC: Government Printing Office).

Warren, Jr. A. J., (1980), Comments, in: Pechman, J. ed., ibid, 120-125.

Whalley, J., 1985, “Allocative and distributive effects of consumption”, in: J. Mintz, ed., Report of the policy forum on tax reform and the consumption taxation, (John Deutsch Institute for the Study of Economic Policy, Queen's University).

Varian H.R. (1980), "Redistributive taxation as social insurance." Journal of Public Economics, 31, $237-51$.

Vickrey, W., (1964), "Principles of Efficiency: Discussion," American Economic Review, P\&P, 54, 88-92.

Wildasin, D. (1990), “R. M. Haig: Pioneer Advocate of Expenditure Taxation?”, J of Economic Literature, 28, 649-660.

Zodrow, G. R., (1995), "Taxation, Uncertainty and the Choice of a Consumption Tax Base", J of Public Economics, 58(2), 257-66. 


\title{
CESifo Working Paper Series
}

\author{
(for full list see www.cesifo.de)
}

917 Jan C. van Ours, Has the Dutch Miracle Come to an End?, April 2003

918 Bertil Holmlund, The Rise and Fall of Swedish Unemployment, April 2003

919 Bernd Huber and Marco Runkel, Optimal Design of Intergovernmental Grants under Asymmetric Information, April 2003

920 Klaus Wälde, Endogenous Business Cycles and Growth, April 2003

921 Ramon Castillo and Stergios Skaperdas, All in the Family or Public? Law and Appropriative Costs as Determinants of Ownership Structure, April 2003

922 Peter Fredriksson and Bertil Holmlund, Improving Incentives in Unemployment Insurance: A Review of Recent Research, April 2003

923 Bernard M.S. van Praag and Adam S. Booij, Risk Aversion and the Subjective Time Discount Rate: A Joint Approach, April 2003

924 Yin-Wong Cheung, Kon S. Lai, and Michael Bergman, Dissecting the PPP Puzzle: The Unconventional Roles of Nominal Exchange Rate and Price Adjustment, April 2003

925 Ugo Trivellato and Anna Giraldo, Assessing the 'Choosiness' of Job Seekers. An Exploratory Approach and Evidence for Italy, April 2003

926 Rudi Dornbusch and Stanley Fischer, International Financial Crises, April 2003

927 David-Jan Jansen and Jakob de Haan, Statements of ECB Officials and their Effect on the Level and Volatility of the Euro-Dollar Exchange Rate, April 2003

928 Mario Jametti and Thomas von Ungern-Sternberg, Assessing the Efficiency of an Insurance Provider - A Measurement Error Approach, April 2003

929 Paolo M. Panteghini and Guttorm Schjelderup, Competing for Foreign Direct Investments: A Real Options Approach, April 2003

930 Ansgar Belke, Rainer Fehn, and Neil Foster, Does Venture Capital Investment Spur Employment Growth?, April 2003

931 Assar Lindbeck, Sten Nyberg, and Jörgen W. Weibull, Social Norms and Welfare State Dynamics, April 2003

932 Myrna Wooders and Ben Zissimos, Hotelling Tax Competition, April 2003 
933 Torben M. Andersen, From Excess to Shortage - Recent Developments in the Danish Labour Market, April 2003

934 Paolo M. Panteghini and Carlo Scarpa, Irreversible Investments and Regulatory Risk, April 2003

935 Henrik Jacobsen Kleven and Claus Thustrup Kreiner, The Marginal Cost of Public Funds in OECD Countries. Hours of Work Versus Labor Force Participation, April 2003

936 Klaus Adam, George W. Evans, and Seppo Honkapohja, Are Stationary Hyperinflation Paths Learnable?, April 2003

937 Ulrich Hange, Education Policy and Mobility: Some Basic Results, May 2003

938 Sören Blomquist and Vidar Christiansen, Is there a Case for Public Provision of Private Goods if Preferences are Heterogeneous? An Example with Day Care, May 2003

939 Hendrik Jürges, Kerstin Schneider, and Felix Büchel, The Effect of Central Exit Examinations on Student Achievement: Quasi-experimental Evidence from TIMSS Germany, May 2003

940 Samuel Bentolila and Juan F. Jimeno, Spanish Unemployment: The End of the Wild Ride?, May 2003

941 Thorsten Bayindir-Upmann and Anke Gerber, The Kalai-Smorodinsky Solution in Labor-Market Negotiations, May 2003

942 Ronnie Schöb, Workfare and Trade Unions: Labor Market Repercussions of Welfare Reform, May 2003

943 Marko Köthenbürger, Tax Competition in a Fiscal Union with Decentralized Leadership, May 2003

944 Albert Banal-Estañol, Inés Macho-Stadler, and Jo Seldeslachts, Mergers, Investment Decisions and Internal Organisation, May 2003

945 Kaniska Dam and David Pérez-Castrillo, The Principal-Agent Matching Market, May 2003

946 Ronnie Schöb, The Double Dividend Hypothesis of Environmental Taxes: A Survey, May 2003

947 Erkki Koskela and Mikko Puhakka, Stabilizing Competitive Cycles with Distortionary Taxation, May 2003

948 Steffen Huck and Kai A. Konrad, Strategic Trade Policy and Merger Profitability, May 2003

949 Frederick van der Ploeg, Beyond the Dogma of the Fixed Book Price Agreement, May 2003 
950 Thomas Eichner and Rüdiger Pethig, A Microfoundation of Predator-Prey Dynamics, May 2003

951 Burkhard Heer and Bernd Süssmuth, Cold Progression and its Effects on Income Distribution, May 2003

952 Yu-Fu Chen and Michael Funke, Labour Demand in Germany: An Assessment of NonWage Labour Costs, May 2003

953 Hans Gersbach and Hans Haller, Competitive Markets, Collective Decisions and Group Formation, May 2003

954 Armin Falk, Urs Fischbacher, and Simon Gächter, Living in Two Neighborhoods Social Interactions in the LAB, May 2003

955 Margarita Katsimi, Training, Job Security and Incentive Wages, May 2003

956 Clemens Fuest, Bernd Huber, and Jack Mintz, Capital Mobility and Tax Competition: A Survey, May 2003

957 Edward Castronova, The Price of 'Man' and 'Woman': A Hedonic Pricing Model of Avatar Attributes in a Synthetic World, June 2003

958 Laura Bottazzi and Marco Da Rin, Financing Entrepreneurial Firms in Europe: Facts, Issues, and Research Agenda, June 2003

959 Bruno S. Frey and Matthias Benz, Being Independent is a Great Thing: Subjective Evaluations of Self-Employment and Hierarchy, June 2003

960 Aaron Tornell and Frank Westermann, Credit Market Imperfections in Middle Income Countries, June 2003

961 Hans-Werner Sinn and Wolfgang Ochel, Social Union, Convergence and Migration, June 2003

962 Michael P. Devereux, Measuring Taxes on Income from Capital, June 2003

963 Jakob de Haan, Jan-Egbert Sturm and Bjørn Volkerink, How to Measure the Tax Burden on Labour at the Macro-Level?, June 2003

964 Harry Grubert, The Tax Burden on Cross-Border Investment: Company Strategies and Country Responses, June 2003

965 Kirk A. Collins and James B. Davies, Measuring Effective Tax Rates on Human Capital: Methodology and an Application to Canada, June 2003

966 W. Steven Clark, Using Micro-Data to Assess Average Tax Rates, June 2003

967 Christopher Heady, The 'Taxing Wages' Approach to Measuring the Tax Burden on Labour, June 2003 
968 Michael P. Devereux and Alexander Klemm, Measuring Taxes on Income from Capital: Evidence from the UK, June 2003

969 Bernhard Eckwert and Itzhak Zilcha, The Effect of Better Information on Income Inequality, June 2003

970 Hartmut Egger and Josef Falkinger, The Role of Public Infrastructure for Firm Location and International Outsourcing, June 2003

971 Dag Morten Dalen and Trond E. Olsen, Regulatory Competition and Multi-national Banking, June 2003

972 Matthias Wrede, Tax Deductibility of Commuting Expenses and Residential Land Use with more than one Center, June 2003

973 Alessandro Cigno and Annalisa Luporini, Scholarships or Student Loans? Subsidizing Higher Education in the Presence of Moral Hazard, June 2003

974 Chang Woon Nam, Andrea Gebauer and Rüdiger Parsche, Is the Completion of EU Single Market Hindered by VAT Evasion?, June 2003

975 Michael Braulke and Giacomo Corneo, Capital Taxation May Survive in Open Economies, July 2003

976 Assar Lindbeck, An Essay on Welfare State Dynamics, July 2003

977 Henrik Jordahl and Luca Micheletto, Optimal Utilitarian Taxation and Horizontal Equity, July 2003

978 Martin D. D. Evans and Richard K. Lyons, Are Different-Currency Assets Imperfect Substitutes?, July 2003

979 Thorsten Bayindir-Upmann and Frank Stähler, Market Entry Regulation and International Competition, July 2003

980 Vivek Ghosal, Firm and Establishment Volatility: The Role of Sunk Costs, Profit Uncertainty and Technological Change, July 2003

981 Christopher A. Pissarides, Unemployment in Britain: A European Success Story, July 2003

982 Wolfgang Buchholz, Richard Cornes, and Wolfgang Peters, On the Frequency of Interior Cournot-Nash Equilibria in a Public Good Economy, July 2003

983 Syed M. Ahsan and Panagiotis Tsigaris, Choice of Tax Base Revisited: Cash Flow vs. Prepayment Approaches to Consumption Taxation, July 2003 